\title{
Steroid Therapy and Steroid Response in Autoimmune Pancreatitis
}

\author{
Hiroyuki Matsubayashi ${ }^{1,2, *}$ (D) , Hirotoshi Ishiwatari ${ }^{1}$, Kenichiro Imai ${ }^{1}$, Yoshihiro Kishida ${ }^{1}$, \\ Sayo Ito ${ }^{1}$, Kinichi Hotta ${ }^{1}$, Yohei Yabuuchi ${ }^{1}$, Masao Yoshida ${ }^{1}$, Naomi Kakushima ${ }^{1}$, \\ Kohei Takizawa ${ }^{1}$, Noboru Kawata ${ }^{1}$ and Hiroyuki Ono ${ }^{1}$ \\ 1 Division of Endoscopy, Shizuoka Cancer Center 1007, Shimonagakubo, Nagaizumi, Suntogun, \\ Shizuoka 411-8777, Japan; h.ishiwatari@scchr.jp (H.I.); ke.imai@scchr.jp (K.I.); y.kishida@scchr.jp (Y.K.); \\ sa.ito@scchr.jp (S.I.); k.hotta@scchr.jp (K.H.); y.yabuuchi@scchr.jp (Y.Y.); ma.yoshida@scchr.jp (M.Y.); \\ n.kakushima@scchr.jp (N.K.); k.takizawa@scchr.jp (K.T.); n.kawata@scchr.jp (N.K.); h.ono@scchr.jp (H.O.) \\ 2 Genetic Medicine Promotion, Shizuoka Cancer Center 1007, Shimonagakubo, Nagaizumi, Suntogun, \\ Shizuoka 411-8777, Japan \\ * Correspondence: h.matsubayashi@scchr.jp; Tel.: +81-55-989-5222; Fax: +81-55-989-5692
}

Received: 25 November 2019; Accepted: 25 December 2019; Published: 30 December 2019

\begin{abstract}
Autoimmune pancreatitis (AIP), a unique subtype of pancreatitis, is often accompanied by systemic inflammatory disorders. AIP is classified into two distinct subtypes on the basis of the histological subtype: immunoglobulin G4 (IgG4)-related lymphoplasmacytic sclerosing pancreatitis (type 1) and idiopathic duct-centric pancreatitis (type 2). Type 1 AIP is often accompanied by systemic lesions, biliary strictures, hepatic inflammatory pseudotumors, interstitial pneumonia and nephritis, dacryoadenitis, and sialadenitis. Type 2 AIP is associated with inflammatory bowel diseases in approximately $30 \%$ of cases. Standard therapy for AIP is oral corticosteroid administration. Steroid treatment is generally indicated for symptomatic cases and is exceptionally applied for cases with diagnostic difficulty (diagnostic steroid trial) after a negative workup for malignancy. More than $90 \%$ of patients respond to steroid treatment within 1 month, and most within 2 weeks. The steroid response can be confirmed on clinical images (computed tomography, ultrasonography, endoscopic ultrasonography, magnetic resonance imaging, and ${ }^{18} \mathrm{~F}$-fluorodeoxyglucose-positron emission tomography). Hence, the steroid response is included as an optional diagnostic item of AIP. Steroid treatment results in normalization of serological markers, including IgG4. Short- and long-term corticosteroid treatment may induce adverse events, including chronic glycometabolism, obesity, an immunocompromised status against infection, cataracts, glaucoma, osteoporosis, and myopathy. AIP is common in old age and is often associated with diabetes mellitus (33-78\%). Thus, there is an argument for corticosteroid therapy in diabetes patients with no symptoms. With low-dose steroid treatment or treatment withdrawal, there is a high incidence of AIP recurrence (24-52\%). Therefore, there is a need for long-term steroid maintenance therapy and/or steroid-sparing agents (immunomodulators and rituximab). Corticosteroids play a critical role in the diagnosis and treatment of AIP.
\end{abstract}

Keywords: autoimmune pancreatitis; IgG4; corticosteroid; treatment

\section{Introduction}

Autoimmune pancreatitis (AIP), a unique subtype of pancreatitis, is characterized by focal or diffuse swelling of the pancreas and narrowing of the pancreatic duct, without marked upstream ductal dilation. AIP is particularly common among older males (mean age: 66.3 years), with a male/female ratio of 3.2:1 and an overall prevalence of 4.6 per 100,000 population, with a 1.4 per 100,000 annual 
incidence rate [1]. The symptoms of AIP vary, depending on which organs are associated. However, they generally include weak or mild abdominal pain, general fatigue, weight loss, and jaundice, with various extrapancreatic lesions [2-5]. AIP is often associated with diabetes (33-78\%) due to the impact of chronic pancreatic inflammation on glucose metabolism [6-11].

AIP is categorized into two subtypes based on its histology: lymphoplasmacytic sclerosing pancreatitis (LPSP) (type 1 AIP) and idiopathic duct-centric pancreatic with granulocytic epithelial lesions (IDCP with GEL) (type 2 AIP) [3,12-15]. Table 1 provides information on distinctive clinical features of AIP, such as age, sex, geographic distribution, associated extrapancreatic lesions, and the steroid response and relapse rate. Type 1 AIP is the pancreatic manifestation of immunoglobulin G4 (IgG4)-related disease [16,17], and often develops in older males and is accompanied by systemic, inflammatory, sclerosing lesions, such as those seen in sclerosing cholangitis, interstitial pneumonia and nephritis, dacryoadenitis, and sialadenitis [4]. Type 2 AIP is more common among young or middle-aged patients, and is often associated with ulcerative colitis and rarely with Crohn's disease [18-21]. Serum markers, including immunoglobulin G4 (IgG4), antinuclear antibody, and rheumatoid factor, are frequently elevated in type 1 AIP $[12,13,22]$. There are no reported serological makers for type 2 AIP.

Table 1. Characteristics of type 1 and type 2 AIP.

\begin{tabular}{ccc}
\hline & Type 1 AIP & Type 2 AIP \\
\hline Distribution & Asia $>$ USA, Europe & Europe > USA > Asia \\
Age at onset & 60s-70s & 40s-50s \\
Sex & Male $>$ Female & Male = Female \\
Symptoms & Jaundice, Abdominal pain & Jaundice, Abdominal pain \\
Serology & IgG4, IgG, Autoantibodies & $(-$ ) \\
Pancreatic images & Enlarged (focal, diffuse) & Enlarged (focal, diffuse) \\
Pancreatic histology & LPSP * & IDCP with GEL $\#$ \\
Extrapancreatic lesions & Sclerosing cholangitis, Sialoadenitis, & Inflammatory bowel disease \\
Retroperitoneal fibrosis, Interstitional & nephritis, etc. & Mostly respond \\
Relapse rate & Mostly respond & $0-27 \%$ \\
\hline
\end{tabular}

AIP: autoimmune pancreatitis, IgG: immunogloblin G, ${ }^{*}$ LPSP: lymphoplasmacytic sclerosing pancreatitis, ${ }^{\#}$ IDCP with GEL: idiopathic duct-centritic pancreatitis with granulocyte epithelial lesion.

AIP results in the formation of mass lesions in the pancreas. The differential diagnosis of AIP is vital to distinguish the disease from malignancies (i.e., pancreatic cancer (PC) and malignant lymphomas). A histological examination by endoscopic ultrasonography-guided fine needle aspiration biopsy (EUS-FNAB) [23-25] is mandatory before treatment commencement to avoid unnecessary surgery. The clinical diagnosis is based on the International Consensus Diagnostic Criteria [2,14], which consists of serological, imaging, and pathological findings, as well as the response to steroid therapy. The International Consensus Diagnostic Criteria are considered superior to other diagnostic criteria for AIP in terms of their sensitivity and specificity [26,27].

Oral corticosteroid therapy is commonly used for AIP, unless the cases have severe steroid intolerance $[28,29]$. Glycemic control may also be required in cases with diabetes beforehand or simultaneously with steroid treatment, and pancreaticobiliary drainage is done only in cases with obvious cholangitis or severe pancreatitis [30,31] (transpapillary biliary stenting should be limited in the necessary cases, as a prolonged period of stenting may promote pancreatic stone formation [30]). In cases of severe steroid intolerance or suspected intolerance, treatment with rituximab or immunomodulators is preferred. The treatment strategy can be tailored according to local conditions, as medical insurance for these drugs differs in each country [32]. 


\section{Steroid Response in Diagnosis of AIP}

The steroid response is listed as an optional diagnostic condition among the International Consensus Diagnostic Criteria for AIP [2], as such a response is hardly seen on clinical images obtained from PC cases [33]. Thus, the steroid response aids the diagnosis of atypical AIP cases, especially those with normal serum IgG4 [34]. However, as corticosteroid treatment is effective against IgG4-related inflammatory pseudotumors of the liver [35,36] and lung [37], it can thus further diagnose an AIP mimicking a PC with distant metastases [36]. In cases of AIP with modest pancreatic enlargement, the steroid response is sometimes unclear. In such cases, endoscopic retrograde cholangiopancreatography is needed to confirm subtle improvements in pancreaticobiliary ductal narrowing and to satisfy the diagnostic criteria [38].

Actual cases of mimickers of AIP and atypical AIP are listed in the following sections.

\subsection{Mimickers of AIP}

In contrast to the aforementioned cases, some neoplastic or malignant cases can mimic [39-41] or co-exist with AIP (IgG4-related diseases) [42]. PC is the most common malignancy that mimics focal-type AIP, although tumors of this type can usually be distinguished from AIP in image findings by poor enhancement while still in the delayed phase, as well as from marked dilation of the upstream pancreatic duct $[2,3,43]$. By contrast, pancreatic lymphoma looks like a diffuse-type AIP, as it reveals a sausage-like, enlarged pancreas with diffuse narrowing of the main pancreatic duct [39], together with elevated levels of serum soluble interleukin-2 (IL2) receptor [44]. However, in the daily clinics, we actually encounter malignancies that are difficult to differentiate from AIPs. For instance, a case of pancreatic head cancer, with upstream pancreatic swelling due to the obstructive pancreatitis, mimics diffuse-type AIP and can lure the physician into conducting a EUS-FNAB at the wrong site [45]. A case of a sausage-like pancreas with high-levels of serum IgG4 (344 mg/dL, normal: 5-105 mg/dL) and anti-DNA antibody $(14 \mathrm{IU} / \mathrm{mL}$, normal: $<6.0 \mathrm{IU} / \mathrm{mL}$ ) was identified as adenocarcinoma after evaluation of a forceps biopsy from the stenotic site of the main pancreatic duct [40]. We also need to bear in mind the possibility of a simultaneous co-existence of AIP (or IgG4-related pathology) and pancreatic malignancies; a small invasive cancer within the lesion of AIP [42], and a concomitant pancreatic mixed acinar-ductal adenocarcinoma; and follicular lymphoma accompanied with IgG4-related pathology [46]. In the international guideline, a persistent pancreatic mass is an indication of steroid therapy after the negative work up for pancreatic malignancies by EUS-FNA, even in an asymptomatic case [32].

The pathological mimickers of AIP or IgG4-related diseases, such as Castleman's disease [47], follicular pancreatitis [48], anti-neutrophil cytoplasmic antibody-associated vasculitides [49,50], inflammatory myofibroblastic tumor [51], and lymphoma [52], are listed from the viewpoints of lymphoplasmacytic proliferation.

\subsection{Atypical Cases of AIP and Their Steroid Responses}

As mentioned, images of AIP typically show focal or diffuse pancreatic enlargement, together with a narrowing of the pancreatic duct in the corresponding area, but without marked dilation of the upstream pancreatic duct. Enhancement is poor in the enlarged pancreas at the arterial phase, but the attenuation is usually recovered at the delayed phase on dynamic CT [43]. A capsule-like rim is sometimes visible around the pancreas in cases of AIP, reflecting the marginal fibrosis $[2,3,14]$. An enlarged pancreas dramatically shrinks in response to corticosteroid therapy in $\geq 95 \%$ of AIPs $[28,53,54]$. Vascular invasion is widely believed to represent a malignant finding but is often seen in cases of AIP and is dramatically recanalized by steroid therapy $[55,56]$.

A widespread consensus on AIP image interpretation has now reduced the number of cases with diagnostic difficulty or atypical AIPs; however, a variety of atypical AIPs have been reported. These include a $9 \mathrm{~mm}$, well-demarcated pancreatic mass that was not affecting the main pancreatic duct [57]; a $2 \mathrm{~cm}$ mass protruding inside the main pancreatic duct and mimicking a main duct-type 
intraductal papillary mucinous neoplasm (IPMN) [58,59]; a $3 \mathrm{~cm}$, low-echoic mass concomitant with a branch-type IPMN [60]; a multilocular cyst with progression of symmetric wall thickening during the time course mimicking cancerization of a branch-type IPMN [61]; and a pancreatic mass invading the ascending colon and mimicking invasive pancreatic carcinoma [62]. Many of these lesions were not accurately diagnosed, but some did not undergo unnecessary resection due to a negative workup for malignancies using EUS-FNAB and the sequential confirmation of a steroid response [60,62]. We should also bear in mind the possible occurrence of AIP or AIP-like pancreatitis due to treatment using an immune checkpoint inhibitor [63].

\subsection{Development of Malignancies in the Course of AIP}

Interval malignancies have also been reported in cases of AIP or IgG4-related diseases. For example, Shiokawa et al. [64] reported a recognition of cancer development in $14 \%$ of AIP cases over an average of 3.3 years of observation, with an obviously increased standardized incidence ratio (2.7) that was especially high in the first year of AIP diagnosis (6.1). Similarly, Ikeura et al. [65] reported three cases (4.8\%) of PC development during an average of 95 months of follow up in 63 AIP patients, whereas Ishida et al. [66] reported the development of malignant lymphoma in the parotid gland seven months after the diagnosis of AIP. Even after successful discrimination of AIP from malignancies, clinicians must remain aware of the possible development of cancers $[65,67,68]$ or lymphomas $[68-71]$ during the follow up of the patients with AIP or IgG4-related diseases, as epidemiological $[64,65,67-70]$ or genetic [71] risks have been reported.

\section{Corticosteroid Treatments for AIP}

\subsection{Corticosteroid Therapy (Standard Steroid Therapy)}

The major indication for steroid treatment is the presence of symptoms. The schedule for standard oral steroid treatment is as follows: an initial prednisolone dose of $0.4-0.6 \mathrm{mg} / \mathrm{kg} / \mathrm{day}$ for $2-4$ weeks, reduced by $5 \mathrm{mg} / \mathrm{d}$ every $1-2$ weeks until $10-15 \mathrm{mg} /$ day, and then gradually tapered to a maintenance dose of $2.5-5 \mathrm{mg} /$ day over a period of 2-3 months (Figure 1) [28]. Maintenance treatment with low-dose steroids reduces but does not eliminate the risk of relapses. According to 2010 guidelines for type 1 AIP, after maintenance therapy for 6-12 months, further treatment tapering and withdrawal were recommended [28]. However, current guidelines recommend low-dose ( $5 \mathrm{mg} /$ day) maintenance steroid treatment (MST) for 2-3 years to reduce the relapse rate $(<30 \%)$ [29].

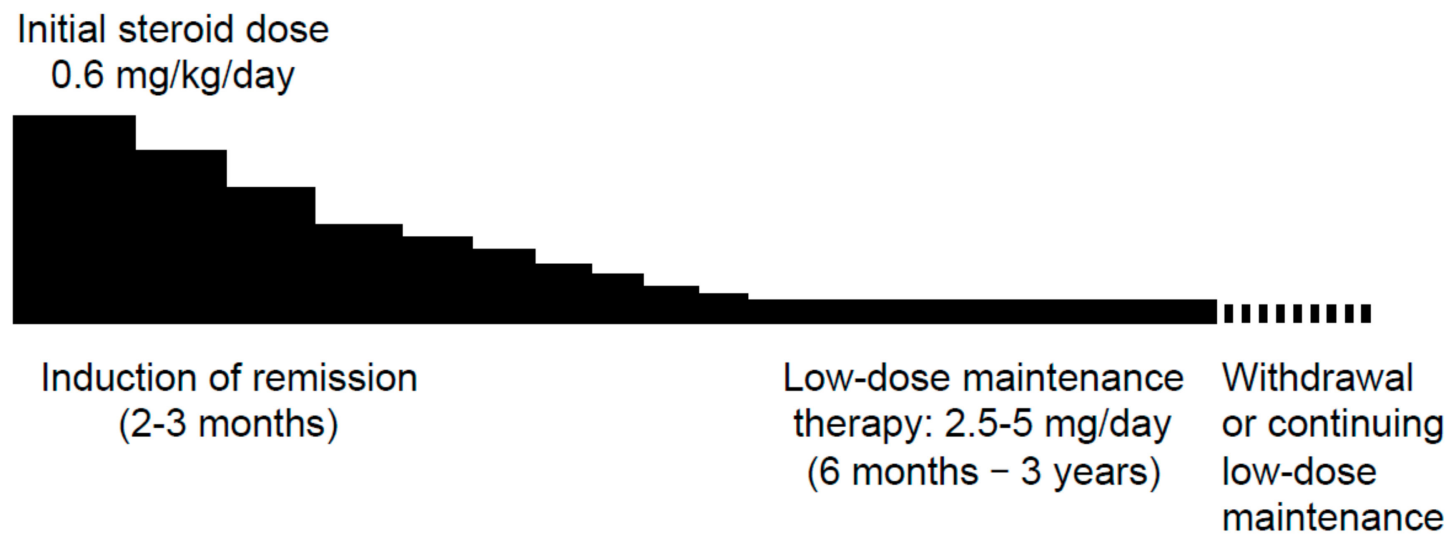

Figure 1. A timetable of standard oral corticosteroid therapy.

\subsection{Rationale for Maintenance Steroid Therapy}

The current guidelines are based mainly on the results of nationwide studies in Japan. Kubota et al. [29] retrospectively analyzed relapse rates in 510 patients (average age: 65.2 years; 
males: $n=393$; females: $n=117$ female) with type 1 AIP in a follow-up of an average of 61.1 months. In their study, oral intake of $2.5-5 \mathrm{mg} /$ day of prednisolone for $\geq 6$ months was defined as low-dose MST. The overall relapse rate in an MST $5 \mathrm{mg}$ /day group (26\%) was significantly lower than that in a non-MST group $(45 \%, p=0.023)$, and the relapse rate was even lower in a $2.5 \mathrm{mg} /$ day MST group $(43 \%$, $p=0.001)$. In their study, the relapse rate almost reached a plateau after 7 years $(43 \%)$ and remained unchanged after 10 years (47\%). During the study period, possible steroid-related complications were recorded in $4 \%$ (20/510) of patients, with the majority of complications developing after 3 years. Several patients experienced poor glycemic control, which was treated with oral antidiabetic agents or insulin injections. Osteoporosis developed in $13(2.5 \%)$ cases. Other complications were steroid myopathy $(n=1)$, fungal infections $(n=3)$, bacterial infections $(n=1)$, cerebral infarctions $(n=1)$, and atherosclerosis $(n=1)$. Many of these complications $(50 \%)$ developed after the accumulated steroid amount exceeded 10,000 mg, and adverse events became severe (15/20) when MST was continued for $>5$ years. In a Japanese nationwide randomized controlled trial, Masamune et al. [72] compared the relapse rate of patients receiving MST (5-7.5 mg/day) for $\geq 3$ years with that of a cessation group (treatment discontinued after 26 weeks). The relapse rate was significantly higher in the cessation group $(58 \%, 11 / 19$ patients within 3 years) than that in the MST group $(23 \%, 7 / 30$ patients) $(p=0.011)$, despite no serious steroid-related events requiring steroid discontinuation in both groups. For long time, it had been believed that type 2 AIP rarely recurs after the initial steroid treatment $[3,12,13,73]$. However, the multicenter Dutch cohort study showed 27\% (3/11) of recurrence in type 2 AIP during the median follow-up of 52 months, treatable by the restart of corticosteroid. They also described the necessity for MST as almost half of the AIP patients (55/107) during the median 74 months of follow-up [21].

MST recommendations are based mainly on the data in the aforementioned studies. However, most cases of AIP occur in elderly patients, and some corticosteroid-related events (e.g., cataracts, glaucoma, and osteoporosis) likely emerge after a long period. Further observations may be needed in these studies. To think of a good response by restarting corticosteroid therapy $[28,29,32,74]$ and an increase in severe complications due to a high cumulative dose of steroids [75], relapse may not necessarily be weighted as a primary matter. As the risk factors predicting relapse have been intensively studied, limiting MST to high-risk patients may be a feasible treatment strategy.

Occasionally, an enlarged pancreas spontaneously shrinks without steroid treatment. Spontaneous regression is most likely to be seen in female type 1 AIP patients with biliary stent placement [76]. Hence, it may be better to follow the disease status for a few weeks in such cases. In principle, steroid treatment should be initiated after a diagnosis of AIP or at least after negative work up by EUS-FNAB, with facile steroid trials for diagnostic purposes avoided [2,14].

\section{Steroid Response in Cases of AIP}

\subsection{Steroid Response Ratio and the Duration until Response Recognition}

The majority of AIP patients respond to steroid treatment (steroid response), with reports of response rates of $97-100 \%[21,53,54]$. This response can be detected in imaging studies as a shrinkage of the enlarged pancreatic parenchyma at 1 month after steroid initiation [54] and often within 2 weeks $(86-100 \%)[33,54]$. Therefore, an initial imaging study is recommended within 1-2 weeks after starting steroid therapy [77]. Response by rituximab can be obtained in cases of relapsed AIP within 15 days; however, it takes more by azathioprine as their treatment effect is weaker [78]. Usually, 3-6 months after steroid treatment initiation for AIP, the thickness of the enlarged pancreas has decreased to $60-70 \%$ of pretreatment phase [30].

\subsection{Biomarkers for Assessing Steroid Response and Relapse}

Serum IgG4 [13,16,22,79-82], IgE [83], soluble IL2-receptor [44] and peripheral blood eosinophils [83], memory B cells [84], and Th2 memory cells [85] have been reported as biomarkers of 
the disease activity of type 1 AIP and IgG4-related diseases. In particular, high level of baseline serum IgG4 $[22,79,82,86]$ and IgE [83] are thought to be predictive markers of relapse. Increased Th2 memory cells may not directly reflect activity of IgG4-related diseases, but may result from the concomitant atopic manifestation [85].

\subsection{Radiological and Ultrasonographic Evaluation for Assessing AIP Response to Steroids}

The steroid response can be detected by imaging studies $[54,55,87,88]$. In terms of imaging studies, 18F-fluorodeoxyglucose-positron emission tomography (FDG-PET) [88] can visualize the steroid response of systemic lesions associated with AIP in a single whole body view, as shown in Figure 2a-c, which depict a case of Mikulicz disease [88]. Figure 2d,e shows early-phase contrast computed tomography (CT) imaging results, which depict dramatic shrinkage of the enlarged pancreatic parenchyma and disappearance of a capsule-like rim and extrapancreatic lesions [55]. Figure $2 \mathrm{f}-\mathrm{k}$ show abdominal ultrasound (US) images of IgG4-associated lesions in the abdomen [54]. Figure 3a,b shows magnetic resonance cholangiopancreatography (MRCP) images of a normalized pancreaticobiliary duct, which was locally and diffusely narrowed by an enlarged pancreas and thickened biliary tract [87].
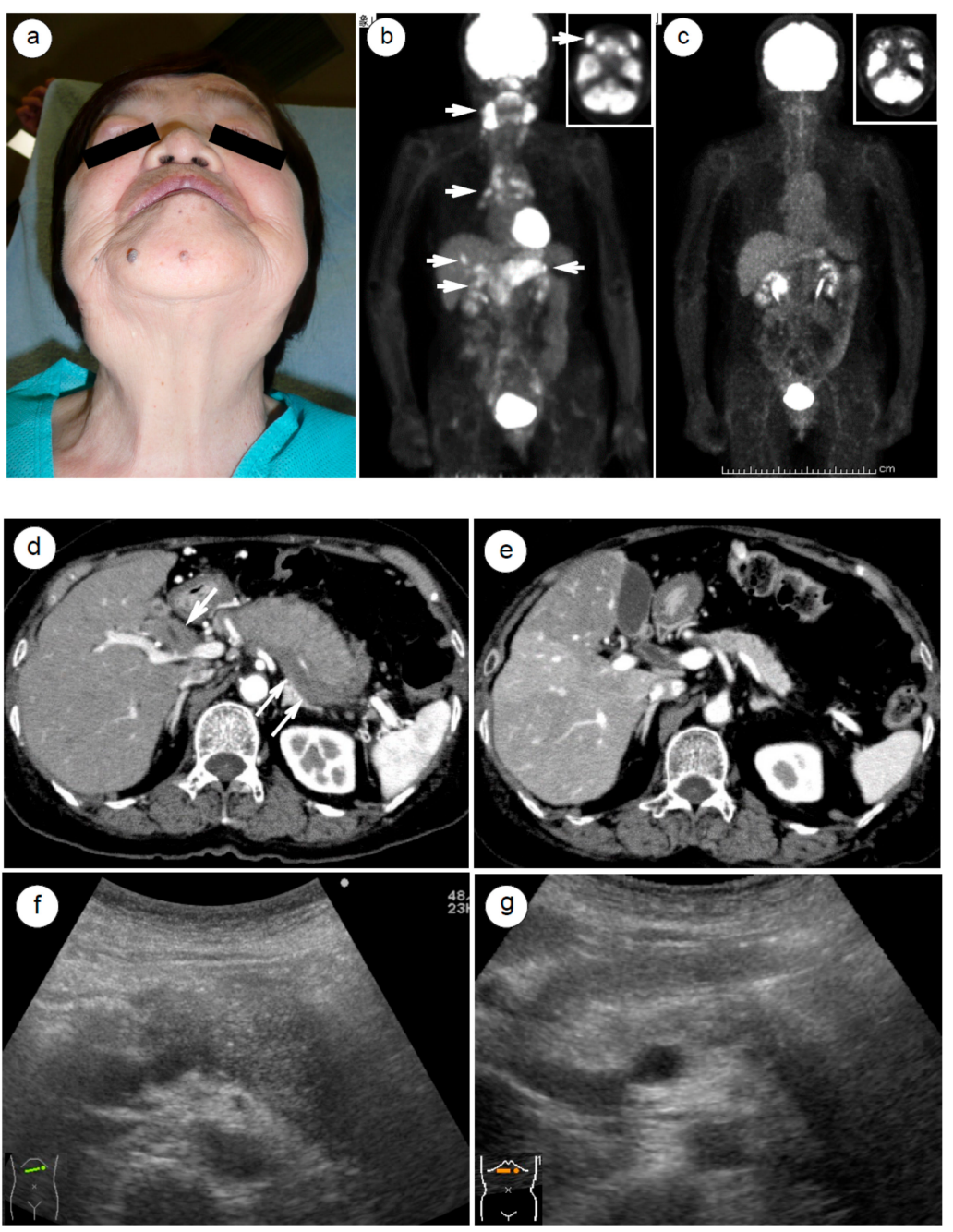

Figure 2. Cont. 

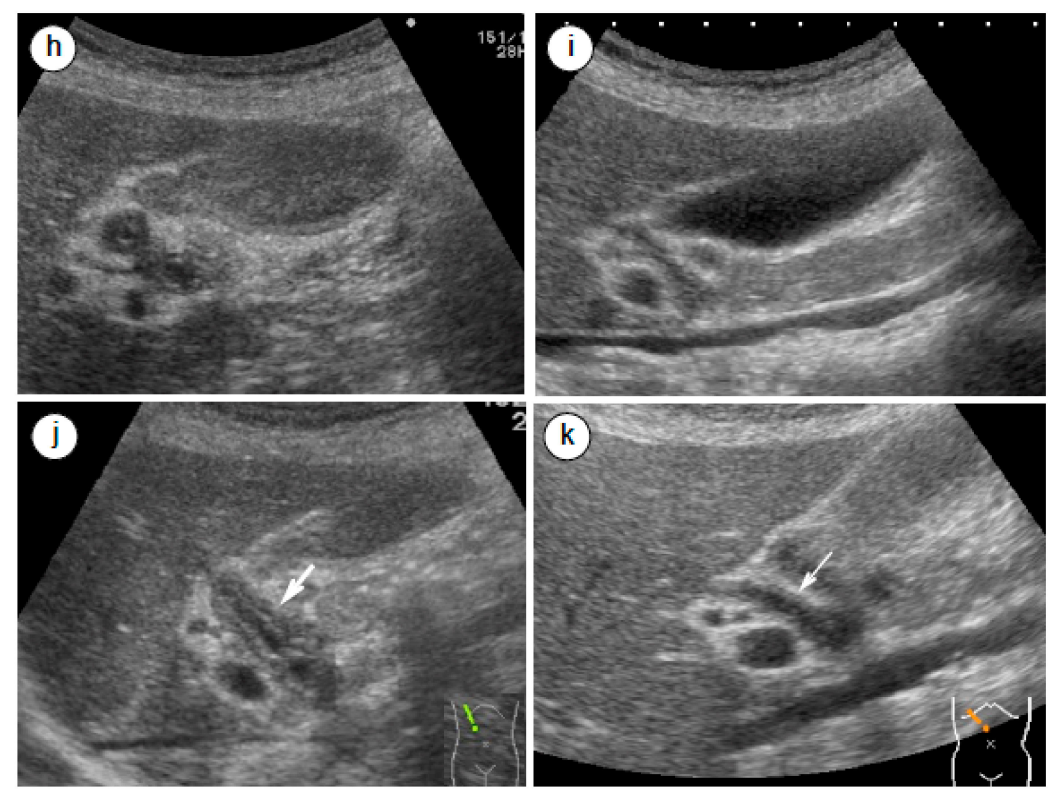

Figure 2. A case of Mikulicz disease with autoimmune pancreatitis (AIP) accompanied by multiple immunoglobulin G4 (IgG4)-related systemic lesions in a 70 year-old female patient. (a) Visualization by 18F-fluorodeoxyglucose-positron emission tomography (FDG-PET) of systemic inflammatory lesions with abnormal FDG uptake (the arrow heads indicate from the top to the bottom: dacryoadenitis, sialadenitis, mediastinum lymphadenopathy, hepatic pseudotumor, autoimmune pancreatitis, and choledocho-chlecystitis. (b) Disappearance of the lesions 3 months after steroid initiation. (c) Computed tomography before steroid treatment demonstrated an enlarged pancreas with a capsule-like rim (thin arrow) and markedly thickened hilar bile duct (thick arrow). (d) Computed tomography 1 year after steroid initiation revealed pancreatic parenchymal shrinkage and improved bile duct thickness. (e) Abdominal ultrasonography before $(\mathbf{f}, \mathbf{h}, \mathbf{j})$ and 2 months after $(\mathbf{g}, \mathbf{i}, \mathbf{k})$ steroid therapy showed a dramatic improvement in the size of the pancreas, as well as wall thicknesses of the gallbladder up to the hilar bile duct (white arrows).
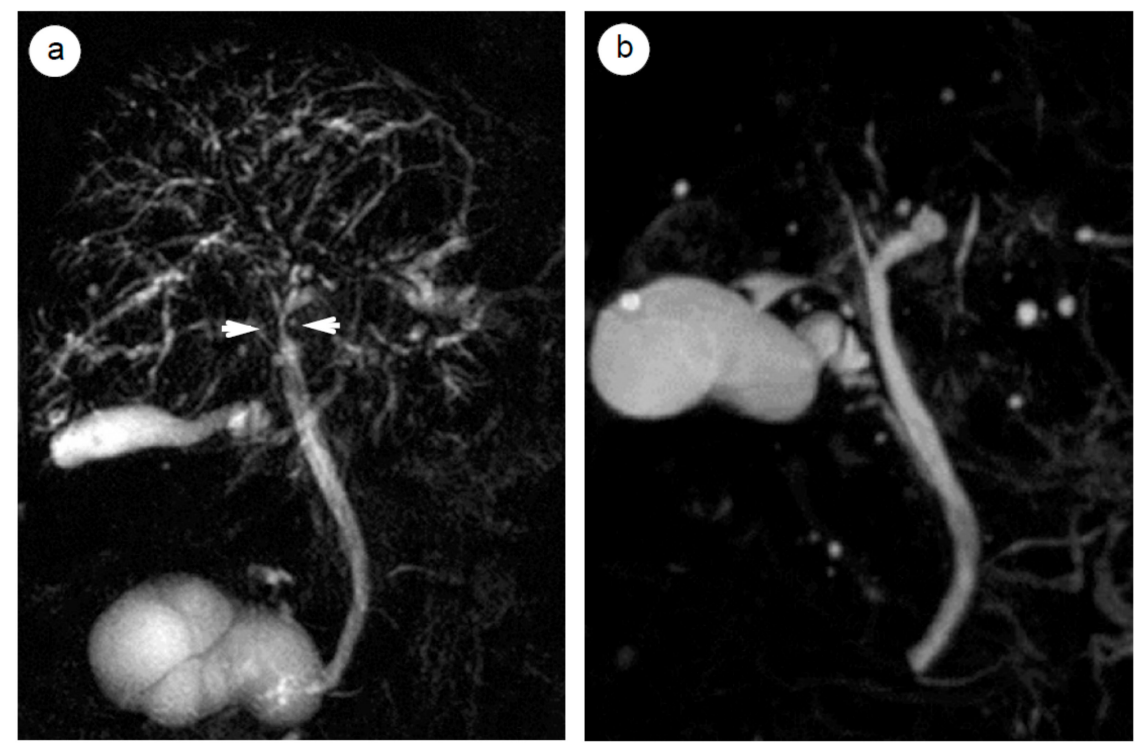

Figure 3. A case of focal-type AIP with sclerosing cholangitis at the hilar and intrahepatic bile ducts in a male 70 year-old patient. Magnetic resonance cholangiopancreatography before steroid treatment showed (a) multiple biliary stenosis at the hepatic hilum (arrow heads) and intrahepatic bile ducts, with improvements 3 months after steroid therapy (b). 
As described above, a steroid response can be recognized in various image modalities and is listed as an optional diagnostic condition; therefore, it is a critical diagnostic test for cases in which a definitive diagnosis of AIP cannot be reached. Enhanced CT is a standard modality for high resolution visualization of all AIP-associated lesions in thin-sliced, cross-sectional images without a blind area. Multidetector-row CT can construct maximum intensity projections and multi-planar reconstruction images that project rotatable sagittal and coronal views that provide a three-dimensional depiction of human anatomy. A differential diagnosis from other pancreatic diseases requires high-resolution views with detailed information of the contrast attenuation [89]. For this reason, enhanced CT is the most widely used modality in many clinical departments.

FDG-PET is a suitable modality for identifying systemic lesions associated with AIP in a whole body view. We previously demonstrated that abnormal uptakes of FDG by IgG4-related lesions were minimized or eliminated after steroid therapy [88]. PCs and malignant lymphomas will also sometimes display abnormal FDG uptakes; therefore, this modality can be effective for discriminating AIP from its neoplastic mimickers. For example, Shigekawa et al. [90] demonstrated that about $90 \%$ of PCs and AIPs show abnormal FDG uptakes at the pancreas (SUV max: 6.8 in AIPs and 7.7 in PCs), but a 1 week steroid therapy could weaken or eliminate FDG uptake in all the AIPs, whereas uptake was unchanged in PCs. Hence, sequential FDG-PET images can be used to evaluate the inflammation level of AIP, as well as to differentiate malignancies from AIPs. The drawbacks are the high cost and the high level of radiation exposure.

US is a handy imaging tool for visualizing the emergence and disappearance of most types of IgG4-related inflammatory lesions in the abdomen and body surface [54]. The advantages of US are its versatility, low cost, portability, and convenience, as well as its nonradiative nature that allows even pregnant women to undergo examination. US is utilized in practice for many IgG4-related lesions, including those in the salivary glands, thyroid, breast, urinary tract, aorta, pancreatobiliary tract, other abdominal solid organs, and superficial lymph nodes [54]. However, ultrasound is hindered by the gases that occupy the gastrointestinal tract and lung, and imaging is poor in obese individuals. The quality of US observation depends largely on the target organs, the patient's anatomy, the time available for the examination, and the skill of ultrasound technician.

Endoscopic ultrasonography (EUS) can be used to visualize the steroid response in the pancreatic parenchymal, as well as the ductal findings (e.g., parenchymal hypertrophy, hyperechoic foci, hyperechoic strand, lobularity, and high-echoic margin of the main pancreatic duct) that are often seen in early chronic pancreatitis and that often respond to steroid therapy [91]. These precise findings cannot be clearly seen with abdominal US, suggesting this as a possible advantage of EUS. Accurate sonographic information that can discriminate other pancreatic lesions can also be obtained using contrast enhancement [92] and elastography [93]. The drawbacks of this modality are the necessity for conscious sedation, it is an operator-dependent examination quality, and blind areas can exist after some upper gastrointestinal tract reconstruction surgeries.

MRCP [87] can be used to visualize pancreatobiliary tracts without radiation exposure and without severe complications such as pancreatitis that can possibly occur in response to endoscopic retrograde cholangiography. Recognition of a subtle difference in the width of the main pancreatic duct, either a narrowing or an obstruction of the duct, is critical for the differential diagnosis between AIP and pancreatic cancer, and MRCP, unlike ERCP, cannot definitively elucidate this difference. However, MRCP is useful for confirmation of the steroid response, as a previously non-visualized narrowed pancreatic duct becomes visible after steroid treatment [87]. Contrast-enhanced MRI is also helpful for differentiation between AIPs and PCs, as the contrast of the lesion (between the masses and surrounding normal pancreata) was significantly different between AIPs and PCs, especially at the arterial phase [94]. Preserved vascular attenuation [94], homogeneous enhancement pattern, duct penetrating sign, and apparent diffusion coefficient (ADC) value [95] have been reported to be key features of AIP. 


\subsection{Steroid Response in Pancreatic Cystic Lesions}

Pancreatic cystic lesions are sometimes associated with AIP (10-22\%) [38,96-98], with most of these lesions being retention cysts [99] or pseudocysts [98]. These cystic lesions respond well to steroids and are minimized or disappeared in 67-78\% of cases [38,96-98] (Figure 4a,b). Although most small-sized cysts respond well to steroids, larger cysts $(>55 \mathrm{~mm})$ tend to be incurable without endoscopic treatment $[96,98]$. However, mucinous neoplastic cysts and cancer-associated cysts that often appear in multilocular cysts are resistant to steroid treatment, in contrast to steroid-responsive unilocular cysts in cases of AIP-associated pseudocysts, and thus careful examinations or observations are needed for them [38]. In cases of clinical emergencies, endoscopic drainage, such as transpapillary naso-pancreatic duct drainage [31] or transluminal pancreatic cyst drainage [96,100,101], are recommended when associated with severe abdominal pain [31] and/or infection [100]. The recommended treatment for hemorrhagic cysts is usually surgery [102] or a transvascular intervention.
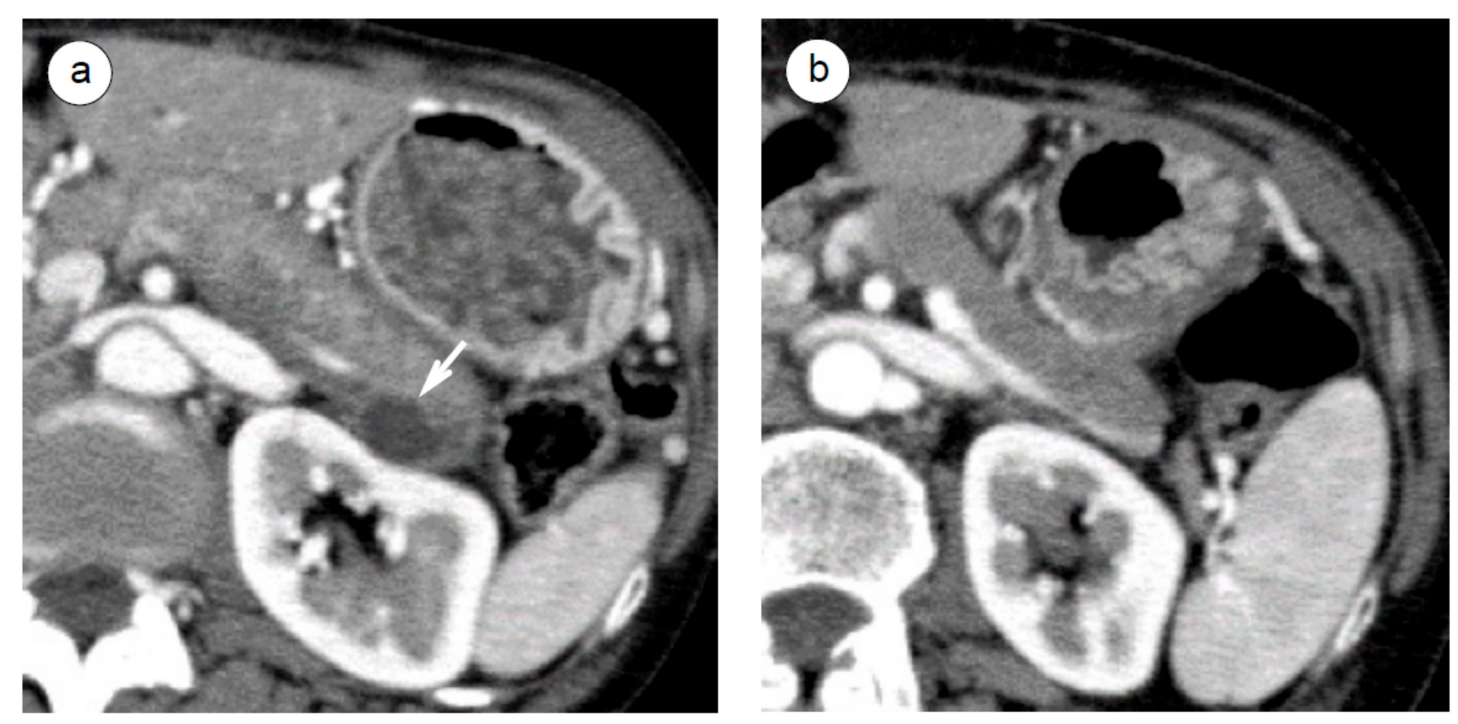

Figure 4. A steroid response in a pancreatic cyst of an AIP patient. Computed tomography demonstrated a unilocular cyst (arrow) at the pancreas tail, $15 \mathrm{~mm}$ in size, at the initial diagnosis of AIP (a). The cyst disappeared after steroid initiation (b).

\subsection{Extrapancreatic Lesions}

A group of extrapancreatic lesions, including dacryoadenitis, sialoadenitis [103], hilar lymphadenopathy [88], interstitial pneumonitis [104], sclerosing cholangitis [21,35,54], retroperitoneal fibrosis [105], and tubulointerstitial nephritis [106], are thought to have a close association with type 1 AIP, whereas inflammatory bowel diseases (e.g., ulcerative colitis and Crohn's disease) are associated with type 2 AIP $[2,4,12,14,21]$. Another group categorized as possible AIP-associated lesions and other possible IgG4-related lesions are listed in Table 2. The latter lesions demonstrate the aggregation of IgG4-positive cells, but the full spectrum of IgG4-related pathology is not always confirmed (e.g., obliterative phlebitis and storiform fibrosis are sometimes lacking) [17]. 
Table 2. Extrapancreatic lesions associated and possibly associated with AIP or IgG4-related lesion.

\begin{tabular}{ccc}
\hline Close Association & $\begin{array}{c}\text { Possible Association with Type 1 } \\
\text { AIP }\end{array}$ & $\begin{array}{c}\text { Possible Association with } \\
\text { IgG4-Related Lesion }\end{array}$ \\
\hline $\begin{array}{c}\text { with type 1 AIP } \\
\text { dacryoadenitis [103] }\end{array}$ & hypophysitis [107] & skull and vertebral lesions \\
sialoadenitis [103] & [108-110] \\
hilar lymphadenopathy [88] & chronic thyroiditis [4] & orbital lesions [109] \\
inflammatory pseudotumors & esophagitis [111] \\
interstitial pneumonitis [104] & breast [113] & sclerosing mesenteritis [114,115] \\
sclerosing cholangitis [21,35,54] & lung [116,117] & Rosai-Dorfman disease [118,119] \\
retroperitoneal fibrosis [105] & liver [35,36,104,120] & gastroenteritis [121] \\
tubulointerstitial nephritis [106] & gastric ulcer [4] & vasculitis [122] \\
& swelling of the papilla of Vater & neuropathy [124] \\
with type 2 AIP & hepatopathy [35] & myopathy [125] \\
inflammatory bowel diseases & aortitis [35] & dermatitis [126] \\
chondritis [127]
\end{tabular}

AIP: autoimmune pancreatitis.

\subsection{Clinical Emergency in Cases of AIP or IgG4-Related Diseases}

Some AIP-associated extrapancreatic lesions cause severe symptoms or represent a clinical emergency if left untreated. These include facial configuration changes due to dacryoadenitis (Mikulicz disease, Figure 2a) [103], vomiting and loss of consciousness due to hypophysitis [107], dyspnea due to pericarditis-induced effusion and heart failure [130-132], dysuria due to a urinary tract obstruction by retroperitoneal fibrosis [105], rupture of an inflammatory aortic aneurysm and periaortitis [35,54,132], and bleeding of gastric varices due to splenic vein obstruction by pancreatic mass involvement $[55,133]$. Clinicians must bear in mind that these aggressive conditions may occur in cases of type 1 AIP or IgG4-related diseases and that corticosteroids are effective and easy to use, especially in the early stage or prior to an emergency.

By contrast, some of our cases of IgG4-related diseases demonstrated adverse events after steroid treatment, namely, a case of IgG4-related mesenteric pseudotumor causing intestinal perforation due to the excessive steroid response [115] and a case of IgG4-related hepatic pseudotumor developing an abscess, probably due to the combined hyperglycemic and ischemic conditions [120]. Clinicians also need to stay aware of any adverse events that might possibly occur after steroid therapy.

\section{Steroid Therapy for Diabetic Control in AIP Patients}

Various adverse events associated with long-term low- to medium-dose oral corticosteroids have been reported: osteoporosis, myopathy, glucose intolerance and diabetes, fat redistribution, suppression of sex hormone secretion, dyslipidemia, atherosclerosis, cardiovascular diseases, hypertension, alopecia, cutaneous atrophy, acne, cataract, glaucoma, peptic ulcer, infections, psychosis, mood disturbances, headaches, vertigo, and tinnitus [134]. Many studies in the last decade have investigated the effect of corticosteroid treatment among AIP patients on diabetes [7-11,135]. According to a number of studies, many AIP patients also have diabetes mellitus (DM) (33-78\%) at the time of their initial AIP diagnosis [6-11]. A nationwide survey in Japan in 2006 found that $55 \%$ of patients with AIP had simultaneous onset of DM [9]. Furthermore, 36\% of AIP patients who had DM prior to AIP onset improved glycemic control by standard corticosteroid therapy [9]. These findings were supported by 3 year follow-up data, which revealed a diabetic improvement after steroid treatment in $63 \%$ (10/16) of patients [10]. Hirano et al. [7] applied the glucagon tolerance test ( $\triangle \mathrm{CPR})$, insulin secretion 
test (HOMA-beta), and insulin resistance test (HOMA-R) in 47 patients with AIP. They assessed glucose tolerance via the $\triangle \mathrm{CPR}$ test 1 month after steroid administration, and HOMA-beta and HOMA-R were examined during the following 60 months. Glucose tolerance improved in $13 \%$ of patients and was aggravated and unchanged in $19 \%$ and $68 \%$ of patients, respectively. Insulin secretion (HOMA-beta) improved significantly in $44-56 \%$ of patients, whereas insulin resistance was significantly aggravated (HOMA-R: 1.30-1.78). On the basis of these data and that of another study [11], the authors recommended steroid treatment at an early stage, especially for AIP patients with glucose intolerance. Masuda et al. [8] examined the diabetic status of 31 AIP patients who underwent steroid treatment and concluded that new onset of diabetes or worsened control of diabetes was common in patients with an atrophic pancreas after steroid induction. To sum up these study results, steroid treatment is recommended for AIP patients with diabetes. However, further studies are needed to clarify the pretreatment characteristics of patients who will not benefit from steroid treatment.

\section{Recurrence of AIP and Factors Associated with Recurrence}

As mentioned above, relapse occurs in $24-52 \%$ of type 1 AIP cases $[22,29,72-74,79-81,136-$ $144]$ and $0-27 \%$ of type 2 AIP cases $[21,73,78]$ after cessation of corticosteroid treatment or dose tapering of corticosteroids. Identification of characteristics or risk factors for relapse is critical, as unnecessary steroid treatment in patients in whom recurrence is unlikely should be avoided. To date, several factors for predicting AIP relapse have been reported. These include a high level of serum IgG4 [22,79]; extrapancreatic lesions [78,80,136,137], especially proximal bile duct stenosis [73,136,138]; retroperitoneal fibrosis [139]; dacryoadenitis/sialadenitis [140]; jaundice [141]; discontinuation of steroid therapy $[138,142,143]$; a small reduction in the level of serum sIgG4 3-4 months after steroid initiation [80,81]; and a low level of pancreatic shrinkage following steroid treatment [144]. Maintenance corticosteroid therapy, with or without steroid-sparing agents, is recommended for type 1 AIP patients with factors predictive of relapse, although the therapeutic period is unclear.

\section{Treatment Strategies for Steroid Refractory Cases}

A small proportion of AIP patients exhibit no steroid response $[53,54,74]$. In other AIP patients, long-term steroid treatment is contraindicated or patients are refractory to standard corticosteroid therapy. In such cases, rituximab is a good alternative therapeutic choice $[78,145,146]$. A recent French study recommended to use rituximab for the treatment of recurrent AIP cases, as an efficacy rate was significantly higher by rituximab $(94 \%, 16 / 17)$ than immunomodulators (azathioprine etc.) $(67 \%, 14 / 21$; $p=0.03$ ) [78]. However, immunomodulators (azathioprine, cyclosporine A, and rapamycin) [21,147] are relatively cheaper and can be used to reduce the lifetime cumulative steroid dosage [32,145]. Unlike rituximab, monotherapy with immunomodulators is not fully effective [145]. Thus, these steroid-sparing agents are used in combination with low-dose steroids [145]. Disease-modifying antirheumatic drugs (DMARDs), such as methotrexate [148] and tacrolimus [149], are also thought of as a treatment choice for the steroid-resistant cases.

The use of immunosuppressants, such as immunomodulators, rituximab, and corticosteroids, in patients with occult hepatitis B virus infection (serum anti-Hepatitis B surface (HBs) antibody positive or anti-Hepatitis $B$ core $(\mathrm{HBc}$ ) antibody positive and HBs antigen negative) should be carefully monitored by quantification of serum hepatitis B virus-DNA, as the virus can be reactivated by immunosuppressive agents [150].

Although rituximab and immunomodulators are used in Western countries, they are not commonly used in Japan because they are not covered by medical insurance plans. In patients refractory to standard steroid therapy in Japan, steroid mini-pulse therapy (two courses of methylprednisolone 500 $\mathrm{mg} /$ day for 3 day, with a 4 day interval) is used [151,152]. 


\section{Conclusions}

Corticosteroids are the standard treatment for symptomatic cases of AIP. Steroid therapy also needs to be considered for asymptomatic patients with diabetes, as it improves glycemic control in many patients in the long term. Although a simple steroid trial before the negative work up of malignancies should be prohibited, a steroid response will support the diagnosis of AIP and is incorporated into the optional diagnostic criteria of AIP. Prolonged low-dose maintenance therapy ( $5 \mathrm{mg} /$ day for 3 years) is recommended for AIP, especially for patients with known risks for recurrence. However, the risk of corticosteroid-associated adverse events, as well as the lifetime cumulative steroid dose, must be considered. To reduce the risk of adverse events and the lifetime cumulative steroid dose, the use of steroid-sparing agents (immunomodulators and rituximab) is an alternative treatment strategy.

Author Contributions: H.M. drafted the paper and the other authors commented on this work. All authors have read and agreed to the published version of the manuscript.

Funding: This research received no external funding.

Conflicts of Interest: The authors declare no conflict of interest.

\section{References}

1. Kanno, A.; Masamune, A.; Okazaki, K.; Kamisawa, T.; Kawa, S.; Nishimori, I.; Tsuji, I.; Shimosegawa, T. Nationwide Epidemiological Survey of Autoimmune Pancreatitis in Japan in 2011. Pancreas 2015, 44, 535-539. [CrossRef] [PubMed]

2. Shimosegawa, T.; Chari, S.T.; Frulloni, L.; Kamisawa, T.; Kawa, S.; Mino-Kenudson, M.; Kim, M.-H.; Kippel, G.; Lerch, M.M.; Lhr, M.; et al. International Consensus Diagnostic Criteria for autoimmune pancreatitis-Guidelines of the International Association of Pancreatology. Pancreas 2011, 40, 352-358. [CrossRef] [PubMed]

3. Okazaki, K.; Tomiyama, T.; Mitsuyama, T.; Sumimoto, K.; Uchida, K. Diagnosis and classification of autoimmune pancreatitis. Autoimmun. Rev. 2014, 13, 451-458. [CrossRef] [PubMed]

4. Kawa, S.; Okazaki, K.; Kamisawa, T.; Shimosegawa, T.; Tanaka, M.; Working members of Research Committee for Intractable Pancreatic Disease and Japan Pancreas Society. Japanese consensus guidelines for management of autoimmune pancreatitis: II. Extrapancreatic lesions, differential diagnosis. J. Gastroenterol. 2010, 45, 355-369. [CrossRef]

5. Kamisawa, T.; Ryu, J.K.; Kim, M.H.; Okazaki, K.; Shimosegawa, T.; Chung, J.B. Recent Advances in the Diagnosis and Management of Autoimmune Pancreatitis: Similarities and Differences in Japan and Korea. Gut Liver 2013, 7, 394-400. [CrossRef]

6. Ito, T.; Otsuki, M.; Itoi, T.; Shimosegawa, T.; Funakoshi, A.; Shiratori, K.; Naruse, S.; Kuroda, Y. The Research Committee of Intractable Diseases of the Pancreas Pancreatic diabetes in a follow-up survey of chronic pancreatitis in Japan. J. Gastroenterol. 2007, 42, 291-297. [CrossRef]

7. Hirano, K.; Isogawa, A.; Tada, M.; Isayama, H.; Takahara, N.; Miyabayashi, K.; Mizuno, S.; Mohri, D.; Kawakubo, K.; Sasaki, T.; et al. Long-Term Prognosis of Autoimmune Pancreatitis in Terms of Glucose Tolerance. Pancreas 2012, 41, 691-695. [CrossRef]

8. Masuda, A.; Shiomi, H.; Matsuda, T.; Takenaka, M.; Arisaka, Y.; Azuma, T.; Kutsumi, H. The relationship between pancreatic atrophy after steroid therapy and diabetes mellitus in patients with autoimmune pancreatitis. Pancreatology 2014, 14, 361-365. [CrossRef]

9. Nishimori, I.; Tamakoshi, A.; Kawa, S.; Tanaka, S.; Takeuchi, K.; Kamisawa, T.; Saisho, H.; Hirano, K.; Okamura, K.; Yanagawa, N.; et al. Influence of steroid therapy on the course of diabetes mellitus in patients with autoimmune pancreatitis: Findings from a nationwide survey in Japan. Pancreas 2006, 32, $244-248$. [CrossRef]

10. Miyamoto, Y.; Kamisawa, T.; Tabata, T.; Hara, S.; Kuruma, S.; Chiba, K.; Inaba, Y.; Kuwata, G.; Fujiwara, T.; Egashira, H.; et al. Short and Long-Term Outcomes of Diabetes Mellitus in Patients with Autoimmune Pancreatitis after Steroid Therapy. Gut Liver 2012, 6, 501-504. [CrossRef] 
11. Noguchi, K.; Nakai, Y.; Mizuno, S.; Isayama, H.; Hirano, K.; Kanai, S.; Nakamura, T.; Uchino, R.; Takahara, N.; Kogure, H.; et al. Insulin secretion improvement during steroid therapy for autoimmune pancreatitis according to the onset of diabetes mellitus. J. Gastroenterol. 2019, 1-7. [CrossRef] [PubMed]

12. Kamisawa, T.; Chari, S.T.; Lerch, M.M.; Kim, M.-H.; Gress, T.M.; Shimosegawa, T. Recent advances in autoimmune pancreatitis: Type 1 and type 2. Gut 2013, 62, 1373-1380. [CrossRef] [PubMed]

13. Klöppel, G.; Detlefsen, S.; Chari, S.T.; Longnecker, D.S.; Zamboni, G. Autoimmune pancreatitis: The clinicopathological characteristics of the subtype with granulocytic epithelial lesions. J. Gastroenterol. 2010, 45, 787-793. [CrossRef] [PubMed]

14. Matsubayashi, H.; Kakushima, N.; Takizawa, K.; Tanaka, M.; Imai, K.; Hotta, K.; Ono, H. Diagnosis of autoimmune pancreatitis. World J. Gastroenterol. 2014, 20, 16559-16569. [CrossRef]

15. Detlefsen, S.; Zamboni, G.; Frulloni, L.; Feyerabend, B.; Braun, F.; Gerke, O.; Schlitter, A.M.; Esposito, I.; Klöppel, G. Clinical features and relapse rates after surgery in type 1 autoimmune pancreatitis differ from type 2: A study of 114 surgically treated European patients. Pancreatology 2012, 12, 276-283. [CrossRef]

16. Culver, E.L.; Sadler, R.; Simpson, D.; Cargill, T.; Makuch, M.; Bateman, A.C.; Ellis, A.J.; Collier, J.; Chapman, R.W.; Klenerman, P.; et al. Elevated Serum IgG4 Levels in Diagnosis, Treatment Response, Organ Involvement, and Relapse in a Prospective IgG4-Related Disease UK Cohort. Am. J. Gastroenterol. 2016, 111, 733-743. [CrossRef]

17. Deshpande, V.; Zen, Y.; Chan, J.K.; Yi, E.; Sato, Y.; Yoshino, T.; Klöppel, G.; Heathcote, J.G.; Khosroshahi, A.; Ferry, J.; et al. Consensus statement on the pathology of IgG4-related disease. Mod. Pathol. 2012, 25, 1181-1192. [CrossRef]

18. Serrero, M.; Abitbol, V.; Allez, M.; Amiot, A.; Barthet, M.; Beaugerie, L.; Bellaiche, G.; Bouguen, G.; Bouhnik, Y.; Bourreille, A.; et al. Features of Autoimmune Pancreatitis Associated With Inflammatory Bowel Diseases. Clin. Gastroenterol. Hepatol. 2018, 16, 59-67.

19. Hart, P.A.; Levy, M.J.; Smyrk, T.C.; Takahashi, N.; Abu Dayyeh, B.K.; Clain, J.E.; Gleeson, F.C.; Pearson, R.K.; Petersen, B.T.; Topazian, M.D.; et al. Clinical profiles and outcomes in idiopathic duct-centric chronic pancreatitis (type 2 autoimmune pancreatitis): The Mayo Clinic experience. Gut 2016, 65, 1702-1709. [CrossRef]

20. Kawa, S.; Okazaki, K.; Notohara, K.; Watanabe, M.; Shimosegawa, T.; Study Group for Pancreatitis Complicated with Inflammatory Bowel Disease organized by The Research Committee for Intractable Pancreatic Disease (Chairman: Tooru Shimosegawa) and The Research Committee for Intractable Inflammatory Bowel Disease (Chairman: Mamoru Watanabe), both of which are Supported by the Ministry of Health, Labour, and Welfare of Japan. Autoimmune pancreatitis complicated with inflammatory bowel disease and comparative study of type 1 and type 2 autoimmune pancreatitis. J. Gastroenterol. 2015, 50, 805-815. [CrossRef]

21. Buijs, J.; Cahen, D.L.; Van Heerde, M.J.; Rauws, E.A.; de Buy Wenniger, L.J.; Hansen, B.E.; Biermann, K.; Verheij, J.; Vleggaar, F.P.; Brink, M.A.; et al. The Long-Term Impact of Autoimmune Pancreatitis on Pancreatic Function, Quality of Life, and Life Expectancy. Pancreas 2015, 44, 1065-1071. [CrossRef]

22. Matsubayashi, H.; Sawai, H.; Kimura, H.; Yamaguchi, Y.; Tanaka, M.; Kakushima, N.; Takizawa, K.; Kadooka, M.; Takao, T.; Hebbar, S.; et al. Characteristics of autoimmune pancreatitis based on serum IgG4 level. Dig. Liver Dis. 2011, 43, 731-735. [CrossRef]

23. Imai, K.; Matsubayashi, H.; Fukutomi, A.; Uesaka, K.; Sasaki, K.; Ono, H. Endoscopic ultrasonography-guided fine needle aspiration biopsy using 22-gauge needle in diagnosis of autoimmune pancreatitis. Dig. Liver Dis. 2011, 43, 869-874. [CrossRef]

24. Matsubayashi, H.; Matsui, T.; Yabuuchi, Y.; Imai, K.; Tanaka, M.; Kakushima, N.; Sasaki, K.; Ono, H. Endoscopic ultrasonography guided-fine needle aspiration for the diagnosis of solid pancreaticobiliary lesions: Clinical aspects to improve the diagnosis. World J. Gastroenterol. 2016, 22, 628-640. [CrossRef]

25. Kanno, A.; Masamune, A.; Fujishima, F.; Iwashita, T.; Kodama, Y.; Katanuma, A.; Ohara, H.; Kitano, M.; Inoue, H.; Itoi, T.; et al. Diagnosis of autoimmune pancreatitis by EUS-guided FNA using a 22-gauge needle: A prospective multicenter study. Gastrointest. Endosc. 2016, 84, 797-804.e1. [CrossRef] [PubMed]

26. Chang, M.-C.; Liang, P.-C.; Jan, I.-S.; Yang, C.-Y.; Tien, Y.-W.; Wei, S.-C.; Wong, J.-M.; Chang, Y.-T. Comparison and validation of International Consensus Diagnostic Criteria for diagnosis of autoimmune pancreatitis from pancreatic cancer in a Taiwanese cohort. BMJ Open 2014, 4, e005900. [CrossRef] [PubMed] 
27. Naitoh, I.; Nakazawa, T.; Hayashi, K.; Miyabe, K.; Shimizu, S.; Kondo, H.; Yoshida, M.; Yamashita, H.; Umemura, S.; Hori, Y.; et al. Clinical Evaluation of International Consensus Diagnostic Criteria for Type 1 Autoimmune Pancreatitis in Comparison With Japanese Diagnostic Criteria 2011. Pancreas 2013, 42, 1238-1244. [CrossRef]

28. Kamisawa, T.; Okazaki, K.; Kawa, S.; Shimosegawa, T.; Tanaka, M.; Research Committee for Intractable Pancreatic Disease and Japan Pancreas Society. Japanese consensus guidelines for management of autoimmune pancreatitis: III. Treatment and prognosis of AIP. J. Gastroenterol. 2010, 45, 471-477. [CrossRef]

29. Kubota, K.; Kamisawa, T.; Okazaki, K.; Kawa, S.; Hirano, K.; Hirooka, Y.; Uchida, K.; Shiomi, H.; Ohara, H.; Shimizu, K.; et al. Low-dose maintenance steroid treatment could reduce the relapse rate in patients with type 1 autoimmune pancreatitis: A long-term Japanese multicenter analysis of 510 patients. J. Gastroenterol. 2017, 52, 955-964. [CrossRef]

30. Matsubayashi, H.; Kishida, Y.; Iwai, T.; Murai, K.; Yoshida, M.; Imai, K.; Yamamoto, Y.; Kikuyama, M.; Ono, $\mathrm{H}$. Transpapillary biliary stenting is a risk factor for pancreatic stones in patients with autoimmune pancreatitis. Endosc. Int. Open 2016, 4, E912-E917. [CrossRef]

31. Matsubayashi, H.; Matsui, T.; Ono, H. Pancreatic Duct Drainage for the Treatment of a Huge Pancreatic Cyst Associated With Autoimmune Pancreatitis. Clin. Gastroenterol. Hepatol. 2015, 13, e151-e152. [CrossRef] [PubMed]

32. Okazaki, K.; Chari, S.T.; Frulloni, L.; Lerch, M.M.; Kamisawa, T.; Kawa, S.; Kim, M.-H.; Levy, P.; Masamune, A.; Webster, G.; et al. International consensus for the treatment of autoimmune pancreatitis. Pancreatol. 2017, 17, 1-6. [CrossRef] [PubMed]

33. Moon, S.-H.; Kim, M.-H.; Park, D.H.; Hwang, C.Y.; Park, S.J.; Lee, S.S.; Seo, D.W.; Lee, S.K. Is a 2-week steroid trial after initial negative investigation for malignancy useful in differentiating autoimmune pancreatitis from pancreatic cancer? A prospective outcome study. Gut 2008, 57, 1704-1712. [CrossRef] [PubMed]

34. Matsubayashi, H.; Imai, K.; Kusumoto, K.; Ono, H. Suspected autoimmune pancreatitis-An indication for steroid treatment? Dig. Liver Dis. 2010, 42, 525-526. [CrossRef] [PubMed]

35. Matsubayashi, H.; Furukawa, H.; Uesaka, K.; Sasaki, K.; Ono, H.; Hruban, R.H. Autoimmune pancreatitis accompanied by cholecystitis, periaortitis and pseudotumors of the liver. Case Rep. Gastroenterol. 2008, 2, 155-161. [CrossRef] [PubMed]

36. Sasahira, N.; Kawabe, T.; Nakamura, A.; Shimura, K.; Shimura, H.; Itobayashi, E.; Asada, M.; Shiratori, Y.; Omata, M. Inflammatory pseudotumor of the liver and peripheral eosinophilia in autoimmune pancreatitis. World J. Gastroenterol. 2005, 11, 922-925. [CrossRef] [PubMed]

37. Campbell, S.N.; Rubio, E.; Loschner, A.L. Clinical Review of Pulmonary Manifestations of IgG4-related Disease. Ann. Am. Thorac. Soc. 2014, 11, 1466-1475. [CrossRef]

38. Matsubayashi, H.; Iwai, T.; Matsui, T.; Wada, T.; Kawata, N.; Ito, H.; Sasaki, K.; Uesaka, K.; Ono, H. Pancreatic cystic lesions with atypical steroid response should be carefully managed in cases of autoimmune pancreatitis. J. Gastroenterol. Hepatol. 2016, 31, 270-276. [CrossRef]

39. Matsubayashi, H.; Takagaki, S.; Otsubo, T.; Iiri, T.; Kobayashi, Y.; Yokota, T.; Shichijo, K.; Iwafuchi, M.; Kijima, H. Pancreatic T-cell lymphoma with high level of soluble interleukin-2 receptor. J. Gastroenterol. 2002, 37, 863-867. [CrossRef]

40. Matsubayashi, H.; Matsunaga, K.; Uesaka, K.; Fukutomi, A.; Sasaki, K.; Furukawa, H.; Ono, H. A case of pancreatic carcinoma with suspected autoimmune pancreatitis. Clin. J. Gastroenterol. 2009, 2, 59-63. [CrossRef]

41. Abarrategi, A.; Mariñas-Pardo, L.; Mirones, I.; Rincón, E.; Garcia-Castro, J. Mesenchymal niches of bone marrow in cancer. Clin. Transl. Oncol. 2011, 13, 611-616. [CrossRef]

42. Motosugi, U.; Ichikawa, T.; Yamaguchi, H.; Nakazawa, T.; Katoh, R.; Itakura, J.; Fujii, H.; Sato, T.; Araki, T.; Shimizu, M. Small invasive ductal adenocarcinoma of the pancreas associated with lymphoplasmacytic sclerosing pancreatitis. Pathol. Int. 2009, 59, 744-747. [CrossRef] [PubMed]

43. Kamisawa, T.; Imai, M.; Chen, P.Y.; Tu, Y.; Egawa, N.; Tsuruta, K.; Okamoto, A.; Suzuki, M.; Kamata, N. Strategy for Differentiating Autoimmune Pancreatitis From Pancreatic Cancer. Pancreas 2008, 37, e62-e67. [CrossRef] [PubMed] 
44. Matsubayashi, H.; Uesaka, K.; Kanemoto, H.; Asakura, K.; Kakushima, N.; Tanaka, M.; Kimura, H.; Ono, H. Soluble IL-2 Receptor, a New Marker for Autoimmune Pancreatitis. Pancreas 2012, 41, 493-496. [CrossRef] [PubMed]

45. Matsubayashi, H.; Sasaki, K.; Nagata, K.; Kanemoto, H.; Kiuchi, R.; Ono, H. Pancreatic carcinoma mimicking diffuse-type autoimmune pancreatitis: Important diagnostic role of pancreatic juice cytology using endoscopic naso-pancreatic drainage. J. Dig. Dis. 2012, 13, 287-290. [CrossRef] [PubMed]

46. Rankovic, B.; Limbaeck-Stokin, C.; Dokic, M.; Stanisavljević, D.; Volavšek, M. Simultaneous occurrence of pancreatic mixed acinar-ductal adenocarcinoma and primary follicular lymphoma of the duodenum, accompanied by increased number of IgG4 plasma cells in tumor-free parenchyma as concomitant IgG4-related disease or reaction to tumor? A case report. Pol. J. Pathol. 2017, 68, 86-91. [PubMed]

47. Zhang, X.; Zhang, P.; Peng, L.; Fei, Y.; Zhang, W.; Feng, R.; Zhang, W. Clinical characteristics of a concurrent condition of IgG4-RD and Castleman's disease. Clin. Rheumatol. 2018, 37, 3387-3395. [CrossRef]

48. Ryu, J.K.; Chung, J.B.; Park, S.W.; Lee, J.K.; Lee, K.T.; Moon, J.H.; Cho, K.B.; Kang, .; D.W, .; Hwang, J.H.; et al. Review of 67 patients with autoimmune pancreatitis in Korea: A multicenter nationwide study. Histopathology 2019, 74, 709-717. [CrossRef]

49. Danlos, F.-X.; Rossi, G.M.; Blockmans, D.; Emmi, G.; Kronbichler, A.; Durupt, S.; Maynard, C.; Luca, L.; Garrouste, C.; Lioger, B.; et al. Antineutrophil cytoplasmic antibody-associated vasculitides and IgG4-related disease: A new overlap syndrome. Autoimmun. Rev. 2017, 16, 1036-1043. [CrossRef]

50. Kawashima, H.; Utsugi, A.; Shibamiya, A.; Iida, K.; Mimura, N.; Ohashi, H.; Hase, R.; Kawakami, M.; Yanagisawa, T.; Hiraguri, M. Consideration concerning similarities and differences between ANCA-associated vasculitis and IgG-4-related diseases: Case series and review of literature. Immunol. Res. 2019, 67, 99-107. [CrossRef]

51. Matsubayashi, H.; Uesaka, K.; Sasaki, K.; Shimada, S.; Takada, K.; Ishiwatari, H.; Ono, H. A Pancreatic Inflammatory Myofibroblastic Tumor with Spontaneous Remission: A Case Report with a Literature Review. Diagnostics 2019, 9, 150. [CrossRef] [PubMed]

52. Nowak, V.; Agaimy, A.; Kristiansen, G.; Gütgemann, I. Increased IgG4-positive plasma cells in nodular-sclerosing Hodgkin lymphoma: A diagnostic pitfall. Histopathology 2019, 76, 244-250. [CrossRef] [PubMed]

53. Kamisawa, T.; Shimosegawa, T.; Okazaki, K.; Nishino, T.; Watanabe, H.; Kanno, A.; Okumura, F.; Nishikawa, T.; Kobayashi, K.; Ichiya, T.; et al. Standard steroid treatment for autoimmune pancreatitis. Gut 2009, 58, 1504-1507. [CrossRef] [PubMed]

54. Matsubayashi, H.; Yoneyama, M.; Nanri, K.; Sugimoto, S.; Shinjo, K.; Kakushima, N.; Tanaka, M.; Ito, S.; Takao, M.; Ono, H. Determination of steroid response by abdominal ultrasound in cases with autoimmune pancreatitis. Dig. Liver Dis. 2013, 45, 1034-1040. [CrossRef]

55. Matsubayashi, H.; Uesaka, K.; Kanemoto, H.; Aramaki, T.; Nakaya, Y.; Kakushima, N.; Ono, H. Reduction of splenic volume by steroid therapy in cases with autoimmune pancreatitis. J. Gastroenterol. 2013, 48, 942-950. [CrossRef]

56. Ishikawa, T.; Itoh, A.; Kawashima, H.; Ohno, E.; Itoh, Y.; Nakamura, Y.; Hiramatsu, T.; Miyahara, R.; Ohmiya, N.; Haruta, J.; et al. Peripancreatic vascular involvements of autoimmune pancreatitis. J. Gastroenterol. Hepatol. 2012, 27, 1790-1795. [CrossRef]

57. Koshita, S.; Ito, K.; Fujita, N.; Noda, Y.; Kobayashi, G.; Horaguchi, J.; Kato, Y.; Yamashita, Y.; Kanno, Y.; Ogawa, T. Localized autoimmune pancreatitis, $9 \mathrm{~mm}$ in size, without strictures of the main pancreatic duct. Gastrointest. Endosc. 2012, 75, 920-922. [CrossRef]

58. Fujie, S.; Matsubayashi, H.; Ishiwatari, H.; Hazama, H.; Ito, T.; Sasaki, K.; Ono, H. Intraductal Tubulopapillary Epithelial Proliferation Associated with Type 1 Autoimmune Pancreatitis. J. Gastrointestin Liver Dis. 2018, 27, 83-87.

59. Nakaji, S.; Hirata, N.; Fujii, H.; Iwaki, K.; Shiratori, T.; Kobayashi, M.; Wakasugi, S.; Ishii, E.; Takeyama, H.; Hoshi, K. A case of focal autoimmune pancreatitis (AIP) mimicking an intraductal papillary mucinous neoplasm (IPMN). Clin. J. Gastroenterol. 2013, 6, 329-333. [CrossRef] 
60. Koshita, S.; Noda, Y.; Ito, K.; Kanno, Y.; Ogawa, T.; Masu, K.; Masaki, Y.; Kusunose, H.; Sakai, T.; Murabayashi, T.; et al. Branch Duct Intraductal Papillary Mucinous Neoplasms of the Pancreas Involving Type 1 Localized Autoimmune Pancreatitis with Normal Serum IgG4 Levels Successfully Diagnosed by Endoscopic Ultrasound-guided Fine-needle Aspiration and Treated without Pancreatic Surgery. Intern. Med. 2017, 56, 1163-1167.

61. Kaneko, J.; Matsubayashi, H.; Satoh, T.; Sato, J.; Takinami, M.; Ishiwatari, H.; Uesaka, K.; Abe, M.; Sasaki, K.; Ono, H. Multilocular Cyst of Type 1 Autoimmune Pancreatitis Masquerading as Cancerization of Intraductal Papillary Mucinous Neoplasm. Intern. Med. 2019, 3561-19. [CrossRef] [PubMed]

62. Matsubayashi, H.; Kishida, Y.; Yoshida, Y.; Yoshida, M.; Tanaka, Y.; Igarashi, K.; Imai, K.; Ono, H. Autoimmune pancreatitis with colonic stenosis: An unusual complication and atypical pancreatographic finding. BMC Gastroenterol. 2014, 14, 173. [CrossRef] [PubMed]

63. Kasahara, C.; Wada, Y.; Matsuo, M.; Machida, K.; Matsushita, A.; Ito, H. A Case of Pancreatitis with a Similar Course to Autoimmune Pancreatitis Occurring After Pembrolizumab Therapy in a Patient with Non-small Cell Lung Cancer. Haigan 2018, 58, 344-348. [CrossRef]

64. Shiokawa, M.; Kodama, Y.; Yoshimura, K.; Kawanami, C.; Mimura, J.; Yamashita, Y.; Asada, M.; Kikuyama, M.; Okabe, Y.; Inokuma, T.; et al. Risk of Cancer in Patients With Autoimmune Pancreatitis. Am. J. Gastroenterol. 2013, 108, 610-617. [CrossRef] [PubMed]

65. Ikeura, T.; Miyoshi, H.; Uchida, K.; Fukui, T.; Shimatani, M.; Fukui, Y.; Sumimoto, K.; Matsushita, M.; Takaoka, M.; Okazaki, K. Relationship between autoimmune pancreatitis and pancreatic cancer: A single-center experience. Pancreatology 2014, 14, 373-379. [CrossRef]

66. Ishida, M.; Hodohara, K.; Yoshida, K.; Kagotani, A.; Iwai, M.; Yoshii, M.; Okuno, H.; Horinouchi, A.; Nakanishi, R.; Harada, A.; et al. Occurrence of anaplastic large cell lymphoma following IgG4-related autoimmune pancreatitis and cholecystitis and diffuse large B-cell lymphoma. Int. J. Clin. Exp. Pathol. 2013, 6, 2560-2568.

67. Asano, J.; Watanabe, T.; Oguchi, T.; Kanai, K.; Maruyama, M.; Ito, T.; Muraki, T.; Hamano, H.; Arakura, N.; Matsumoto, A.; et al. Association Between Immunoglobulin G4-related Disease and Malignancy within 12 Years after Diagnosis: An Analysis after Longterm Followup. J. Rheumatol. 2015, 42, 2135-2142. [CrossRef]

68. Yamamoto, M.; Takahashi, H.; Tabeya, T.; Suzuki, C.; Naishiro, Y.; Ishigami, K.; Yajima, H.; Shimizu, Y.; Obara, M.; Yamamoto, H.; et al. Risk of malignancies in IgG4-related disease. Mod. Rheumatol. 2012, 22, 414-418. [CrossRef]

69. Bledsoe, J.R.; Wallace, Z.S.; Stone, J.H.; Deshpande, V.; Ferry, J.A. Lymphomas in IgG4-related disease: Clinicopathologic features in a Western population. Virchows Arch 2018, 472, 839-852. [CrossRef]

70. Ahn, S.S.; Song, J.J.; Park, Y.-B.; Lee, S.-W. Malignancies in Korean patients with immunoglobulin G4-related disease. Int. J. Rheum. Dis. 2017, 20, 1028-1035. [CrossRef]

71. Din, L.; Sheikh, M.; Kosaraju, N.; Smedby, K.E.; Bernatsky, S.; Berndt, S.I.; Skibola, C.F.; Nieters, A.; Wang, S.; McKay, J.D.; et al. Genetic overlap between autoimmune diseases and non-Hodgkin lymphoma subtypes. Genet. Epidemiol. 2019, 43, 844-863. [CrossRef] [PubMed]

72. Masamune, A.; Nishimori, I.; Kikuta, K.; Tsuji, I.; Mizuno, N.; Iiyama, T.; Kanno, A.; Tachibana, Y.; Ito, T.; Kamisawa, T.; et al. Randomised controlled trial of long-term maintenance corticosteroid therapy in patients with autoimmune pancreatitis. Gut 2017, 66, 487-494. [CrossRef] [PubMed]

73. Sah, R.P.; Chari, S.T.; Pannala, R.; Sugumar, A.; Clain, J.E.; Levy, M.J.; Pearson, R.K.; Smyrk, T.C.; Petersen, B.T.; Topazian, M.D.; et al. Differences in Clinical Profile and Relapse Rate of Type 1 Versus Type 2 Autoimmune Pancreatitis. Gastroenterology 2010, 139, 140-148. [CrossRef]

74. Kamisawa, T.; Okazaki, K.; Kawa, S.; Ito, T.; Inui, K.; Irie, H.; Nishino, T.; Notohara, K.; Nishimori, I.; Tanaka, S.; et al. Amendment of the Japanese Consensus Guidelines for Autoimmune Pancreatitis, 2013 III. Treatment and prognosis of autoimmune pancreatitis. J. Gastroenterol. 2014, 49, 961-970. [PubMed]

75. Shimizu, S.; Naitoh, I.; Nakazawa, T.; Hayashi, K.; Miyabe, K.; Kondo, H.; Nishi, Y.; Yoshida, M.; Umemura, S.; Hori, Y.; et al. Correlation between long-term outcome and steroid therapy in type 1 autoimmune pancreatitis: Relapse, malignancy and side effect of steroid. Scand. J. Gastroenterol. 2015, 50, 1411-1418. [CrossRef]

76. Kubota, K.; Kamisawa, T.; Hirano, K.; Hirooka, Y.; Uchida, K.; Ikeura, T.; Shiomi, H.; Ohara, H.; Shimizu, K.; Arakura, N.; et al. Clinical course of type 1 autoimmune pancreatitis patients without steroid treatment: A Japanese multicenter study of 97 patients. J. Hepatobiliary Pancreat. Sci. 2018, 25, 223-230. 
77. Kawa, S.; Okazaki, K.; Kamisawa, T.; Kubo, K.; Ohara, H.; Hasebe, O.; Fujinaga, Y.; Irisawa, A.; Notohara, K.; Ito, T.; et al. Amendment of the Japanese Consensus Guidelines for Autoimmune Pancreatitis, 2013 II. Extrapancreatic lesions, differential diagnosis. J. Gastroenterol. 2014, 49, 765-784. [CrossRef]

78. Soliman, H.; Vullierme, M.-P.; Maire, F.; Hentic, O.; Ruszniewski, P.; Lévy, P.; Rebours, V. Risk factors and treatment of relapses in autoimmune pancreatitis: Rituximab is safe and effective. United Eur. Gastroenterol. J. 2019, 7, 1073-1083.

79. Kubota, K.; Watanabe, S.; Uchiyama, T.; Kato, S.; Sekino, Y.; Suzuki, K.; Mawatari, H.; Iida, H.; Endo, H.; Fujita, K.; et al. Factors predictive of relapse and spontaneous remission of autoimmune pancreatitis patients treated/not treated with corticosteroids. J. Gastroenterol. 2011, 46, 834-842.

80. Zhu, L.; Xue, H.-D.; Zhang, W.; Wang, Q.; Tan, B.; Lai, Y.-M.; Zheng, W.-Y.; Asbach, P.; Hamm, B.; Denecke, T.; et al. Pancreaticobiliary involvement in treated type 1 autoimmune pancreatitis: Imaging pattern and risk factors for disease relapse. Eur. J. Radiol. 2019, 120, 108673. [CrossRef]

81. Shimizu, K.; Tahara, J.; Takayama, Y.; Akao, J.; Ajihara, T.; Nagao, K.; Shiratori, K.; Tokushige, K. Assessment of the Rate of Decrease in Serum IgG4 Level of Autoimmune Pancreatitis Patients in Response to Initial Steroid Therapy as a Predictor of Subsequent Relapse. Pancreas 2016, 45, 1-1346.

82. Kawa, S.; Ito, T.; Watanabe, T.; Maruyama, M.; Hamano, H.; Maruyama, M.; Muraki, T.; Arakura, N. The Utility of Serum IgG4 Concentrations as a Biomarker. Int. J. Rheumatol. 2012, 2012, 1-4. [CrossRef] [PubMed]

83. Culver, E.L.; Sadler, R.; Bateman, A.C.; Makuch, M.; Cargill, T.; Ferry, B.; Aalberse, R.; Barnes, E.; Rispens, T. Increases in IgE, Eosinophils, and Mast Cells Can be Used in Diagnosis and to Predict Relapse of IgG4-Related Disease. Clin. Gastroenterol. Hepatol. 2017, 15, 1444-1452.e6. [CrossRef] [PubMed]

84. Lanzillotta, M.; Della-Torre, E.; Milani, R.; Bozzolo, E.; Bozzalla-Cassione, E.; Rovati, L.; Arcidiacono, P.G.; Partelli, S.; Falconi, M.; Ciceri, F.; et al. Increase of circulating memory B cells after glucocorticoid-induced remission identifies patients at risk of IgG4-related disease relapse. Arthritis Res. 2018, 20, 222.

85. Mattoo, H.; Della-Torre, E.; Mahajan, V.S.; Stone, J.H.; Pillai, S. Circulating Th2 memory cells in IgG4-related disease are restricted to a defined subset of subjects with atopy. Allergy 2014, 69, 399-402. [CrossRef] [PubMed]

86. Frulloni, L.; Lunardi, C. Serum IgG4 in autoimmune pancreatitis: A marker of disease severity and recurrence? Dig. Liver Dis. 2011, 43, 674-675.

87. Kamisawa, T.; Tu, Y.; Egawa, N.; Okamoto, A.; Kodama, M.; Kamata, N. Can MRCP replace ERCP for the diagnosis of autoimmune pancreatitis? Abdom Imaging 2009, 34, 381-384. [CrossRef]

88. Matsubayashi, H.; Furukawa, H.; Maeda, A.; Matsunaga, K.; Kanemoto, H.; Uesaka, K.; Fukutomi, A.; Ono, H. Usefulness of Positron Emission Tomography in the Evaluation of Distribution and Activity of Systemic Lesions Associated with Autoimmune Pancreatitis. Pancreatology 2009, 9, 694-699. [CrossRef]

89. Kamisawa, T.; Egawa, N.; Nakajima, H.; Tsuruta, K.; Okamoto, A.; Kamata, N.; Funata, N. Comparison of radiological and histological findings in autoimmune pancreatitis. Hepatogastroenterology 2006, 53, 953-956.

90. Shigekawa, M.; Yamao, K.; Sawaki, A.; Hara, K.; Takagi, T.; Bhatia, V.; Nishio, M.; Tamaki, T.; El-Amin, H.; Sayed, Z.-A.; et al. Is (18)F-fluorodeoxyglucose positron emission tomography meaningful for estimating the efficacy of corticosteroid therapy in patients with autoimmune pancreatitis? J. Hepatobiliary Pancreat. Sci. 2010, 17, 269-274. [CrossRef]

91. Okabe, Y.; Ishida, Y.; Kaji, R.; Sugiyama, G.; Yasumoto, M.; Naito, Y.; Toyonaga, A.; Tsuruta, O.; Sata, M. Endoscopic ultrasonographic study of autoimmune pancreatitis and the effect of steroid therapy. J. Hepatobiliary Pancreat. Sci. 2012, 19, 266-273. [PubMed]

92. Cho, M.K.; Moon, S.-H.; Song, T.J.; Kim, R.E.; Oh, D.W.; Park, D.H.; Lee, S.S.; Seo, D.W.; Lee, S.K.; Kim, M.-H. Contrast-Enhanced Endoscopic Ultrasound for Differentially Diagnosing Autoimmune Pancreatitis and Pancreatic Cancer. Gut Liver 2018, 12, 591-596. [CrossRef] [PubMed]

93. Ohno, E.; Hirooka, Y.; Kawashima, H.; Ishikawa, T.; Tanaka, H.; Sakai, D.; Ishizu, Y.; Kuzuya, T.; Nakamura, M.; Honda, T. Feasibility and usefulness of endoscopic ultrasonography-guided shear-wave measurement for assessment of autoimmune pancreatitis activity: A prospective exploratory study. J. Med. Ultrason. 2009, 46, 425-433. [CrossRef] [PubMed]

94. Kwon, J.H.; Kim, J.H.; Kim, S.Y.; Byun, J.H.; Kim, H.J.; Lee, M.-G.; Lee, S.S. Differentiating focal autoimmune pancreatitis and pancreatic ductal adenocarcinoma: Contrast-enhanced MRI with special emphasis on the arterial phase. Eur. Radiol. 2019, 29, 5763-5771. [PubMed] 
95. Choi, S.-Y.; Kim, S.H.; Kang, T.W.; Song, K.D.; Park, H.J.; Choi, Y.-H. Differentiating Mass-Forming Autoimmune Pancreatitis from Pancreatic Ductal Adenocarcinoma on the Basis of Contrast-Enhanced MRI and DWI Findings. Am. J. Roentgenol. 2016, 206, 291-300.

96. Kubota, K.; Fujita, Y.; Sato, T.; Sekino, Y.; Hosono, K.; Kobayashi, N.; Fujisawa, N.; Kagawa, K.; Fujisawa, T.; Matsuhashi, N.; et al. Autoimmune pancreatitis associated with pancreatic cyst: How can we manage it? J. Hepatobiliary Pancreat. Sci. 2014, 21, 902-910.

97. Kuraishi, Y.; Watanabe, T.; Muraki, T.; Ashihara, N.; Ozawa, M.; Nakamura, A.; Kanai, K.; Hamano, H.; Kawa, S. Effectiveness of steroid therapy for pancreatic cysts complicating autoimmune pancreatitis and management strategy for cyst-related complications. Scand. J. Gastroenterol. 2019, 54, 773-779.

98. Donet, J.A.; Barkin, J.A.; Keihanian, T.; Nemeth, Z.; Barkin, J.S. Pancreatic Pseudocysts and Parenchymal Necrosis in Patients With Autoimmune Pancreatitis. Pancreas 2018, 47, 952-957.

99. Matsubayashi, H.; Kubota, K. Pancreatic Cystic Lesions in Cases of Autoimmune Pancreatitis. Pancreas 2019, 48, e14.

100. Chang, K.A.; Kim, T.N.; Lee, S.H. Autoimmune pancreatitis complicated by an infected pseudocyst. Clin. J. Gastroenterol. 2010, 3, 168-173.

101. Yamamoto, K.; Itoi, T.; Sofuni, A.; Tsuchiya, T.; Tsuji, S.; Tanaka, R.; Tonozuka, R.; Honjo, M.; Mukai, S.; Kamada, K.; et al. The Role of Endoscopic Ultrasound-guided Drainage for Autoimmune Pancreatitis-associated Pancreatic Cysts: A Report of Five Cases and a Literature Review. Intern. Med. 2018, 57, 1523-1531. [CrossRef] [PubMed]

102. Kawakami, H.; Kuwatani, M.; Shinada, K.; Yamato, H.; Hirano, S.; Kondo, S.; Yonemori, A.; Itoh, T.; Matsuno, Y.; Asaka, M. Autoimmune pancreatitis associated with hemorrhagic pseudocysts: A case report and literature review. Intern. Med. 2008, 47, 603-608. [CrossRef] [PubMed]

103. Kubota, K.; Wada, T.; Kato, S.; Mozaki, Y.; Yoneda, M.; Fujita, K.; Takahashi, H.; Inamori, M.; Abe, Y.; Kobayashi, N.; et al. Highly Active State of Autoimmune Pancreatitis With Mikulicz Disease. Pancreas 2010, 39, e6-e10. [PubMed]

104. Zen, Y.; Fujii, T.; Sato, Y.; Masuda, S.; Nakanuma, Y. Pathological classification of hepatic inflammatory pseudotumor with respect to IgG4-related disease. Mod. Pathol. 2007, 20, 884-894. [CrossRef]

105. Hara, N.; Kawaguchi, M.; Takeda, K.; Zen, Y. Retroperitoneal disorders associated with IgG4-related autoimmune pancreatitis. World J. Gastroenterol. 2014, 20, 16550-16558. [CrossRef]

106. Salvadori, M.; Tsalouchos, A. Immunoglobulin G4-related kidney diseases: An updated review. World J. Nephrol. 2018, 7, 29-40. [CrossRef]

107. Taniguchi, T.; Hamasaki, A.; Okamoto, M. A case of suspected lymphocytic hypophysitis and organizing pneumonia during maintenance therapy for autoimmune pancreatitis associated with autoimmune thrombocytopenia. Endocr. J. 2006, 53, 563-566. [CrossRef]

108. Detiger, S.E.; Karim, F.; Monserez, D.; Verdijk, R.; van Hagen, M.; Paridaens, D.; van Laar, J. IgG4-related disease of the skull base: A case series of three patients with headache. World Neurosurg. 2019. [CrossRef]

109. Detiger, S.E.; Karim, A.F.; Verdijk, R.M.; Van Hagen, P.M.; Van Laar, J.A.M.; Paridaens, D. The treatment outcomes in IgG4-related orbital disease: A systematic review of the literature. Acta Ophthalmol. 2019, 97, 451-459. [CrossRef]

110. van den Elshout-den, U.D.; Spoto, C.P.E.; De Boer, M.; Leiner, T.; Leavis, H.L.; Leguit, R.J. First Report of IgG4 Related Disease Primary Presenting as Vertebral Bone Marrow Lesions. Front. Immunol. 2019, 10, 1910. [CrossRef]

111. Chan, S.K.; Cheuk, W.; Chan, K.T.; Chan, J.K. IgG4-related sclerosing pachymeningitis: A previously unrecognized form of central nervous system involvement in IgG4-related sclerosing disease. Am. J. Surg. Pathol. 2009, 33, 1249-1252. [CrossRef] [PubMed]

112. Obiorah, I.; Hussain, A.; Palese, C.; Azumi, N.; Benjamin, S.; Ozdemirli, M. IgG4-related disease involving the esophagus: A clinicopathological study. Dis. Esophagus 2017, 30, 1-7. [PubMed]

113. Cheuk, W.; Chan, A.C.L.; Lam, W.-L.; Chow, S.-M.; Crowley, P.; Lloydd, R.; Campbell, I.; Thorburn, M.; Chan, J.K.C. IgG4-related Sclerosing Mastitis: Description of a New Member of the IgG4-related Sclerosing Diseases. Am. J. Surg. Pathol. 2009, 33, 1058-1064. [CrossRef] [PubMed] 
114. Fukuda, M.; Miyake, T.; Matsubara, A.; Ikai, N.; Tanaka, E.; Namura, T.; Wada, Y.; Noujima, M.; Moritani, S.; Murakami, K.; et al. A Case of Sclerosing Mesenteritis Mimicking IgG4-related Disease. Intern. Med. 2019. [CrossRef]

115. Yabuuchi, Y.; Matsubayashi, H.; Matsuzaki, M.; Shiomi, A.; Moriguchi, M.; Kawamura, I.; Ito, I.; Ono, H. Colovesical fistula caused by glucocorticoid therapy for IgG4-related intrapelvic mass. World J. Clin. Cases 2015, 3, 1000-1004. [CrossRef]

116. Matsui, S. IgG4-related respiratory disease. Mod. Rheumatol. 2019, 29, 251-256. [CrossRef]

117. Zen, Y.; Kitagawa, S.; Minato, H.; Kurumaya, H.; Katayanagi, K.; Masuda, S.; Niwa, H.; Fujimura, M.; Nakanuma, Y. IgG4-positive plasma cells in inflammatory pseudotumor (plasma cell granuloma) of the lung. Hum. Pathol. 2005, 36, 710-717.

118. Hoffmann, J.C.; Lin, C.Y.; Bhattacharyya, S.; Weinberg, O.K.; Chisholm, K.M.; Bayerl, M.; Cascio, M.; Venkataraman, G.; Allison, K.; Troxell, M.; et al. Rosai-Dorfman Disease of the Breast With Variable IgG4+ Plasma Cells: A Diagnostic Mimicker of Other Malignant and Reactive Entities. Am. J. Surg. Pathol. 2019, 43, 1653-1660.

119. Tracht, J.; Reid, M.D.; Xue, Y.; Madrigal, E.; Sarmiento, J.M.; Kooby, D.; Alese, O.B.; Krasinskas, A.M. Rosai-Dorfman Disease of the Pancreas Shows Significant Histologic Overlap With IgG4-related Disease. Am. J. Surg. Pathol. 2019, 43, 1536-1546.

120. Shibata, M.; Matsubayashi, H.; Aramaki, T.; Uesaka, K.; Tsutsumi, N.; Sasaki, K.; Ono, H. A case of IgG4-related hepatic inflammatory pseudotumor replaced by an abscess after steroid treatment. BMC Gastroenterol. 2016, 16, 89.

121. Notohara, K.; Kamisawa, T.; Uchida, K.; Zen, Y.; Kawano, M.; Kasashima, S.; Sato, Y.; Shiokawa, M.; Uehara, T.; Yoshifuji, H.; et al. Gastrointestinal manifestation of immunoglobulin G4-related disease: Clarification through a multicenter survey. J. Gastroenterol. 2018, 53, 845-853. [CrossRef] [PubMed]

122. Ma, Y.; Chen, L.; Xu, Y.; Han, Q.; Yu, B.; Yuan, Y.; Zhao, J.; Yang, Y.; Chen, J.; Han, F. Clinical and pathological features of patients with antineutrophil cytoplasmic antibody-associated vasculitides concomitant with IgG4-related disease. Int. J. Rheum. Dis. 2019, 22, 2143-2150.

123. Kubota, K.; Iida, H.; Fujisawa, T.; Ogawa, M.; Inamori, M.; Saito, S.; Kakuta, Y.; Oshiro, H.; Nakajima, A. Clinical Significance of Swollen Duodenal Papilla in Autoimmune Pancreatitis. Pancreas 2007, 35, e51-e60. [PubMed]

124. Ohyama, K.; Koike, H.; Takahashi, M.; Kawagashira, Y.; Iijima, M.; Watanabe, H.; Sobue, G. Immunoglobulin G4-related pathologic features in inflammatory neuropathies. Neurology 2015, 85, 1400-1407. [CrossRef] [PubMed]

125. Anan, R.; Akiyama, M.; Kaneko, Y.; Kikuchi, J.; Suzuki, K.; Matsubara, S.; Takeuchi, T. Polymyositis with elevated serum IgG4 levels and abundant IgG4+ plasma cell infiltration: A case report and literature review. Medicine 2017, 96, e8710.

126. Sato, Y.; Takeuchi, M.; Takata, K.; Ohno, K.; Iwaki, N.; Orita, Y.; Goto, N.; Hida, A.I.; Iwamoto, T.; Asano, N.; et al. Clinicopathologic analysis of IgG4-related skin disease. Mod. Pathol. 2013, 26, 523-532.

127. Yamasue, M.; Nureki, S.-I.; Matsumoto, H.; Kan, T.; Hashimoto, T.; Ushijima, R.; Usagawa, Y.; Kadota, J.-I. Corticosteroid Therapy for a Patient with Relapsing Polychondritis Complicated by IgG4-Related Disease. Tohoku J. Exp. Med. 2016, 239, 223-230.

128. Sawai, H.; Matsubayashi, H.; Tanaka, M.; Yamaguchi, Y.; Ono, H. A case of autoimmune pancreatitis with metachronous appearance of idiopathic thrombocytopenic purpura. Clin. J. Gastroenterol. 2010, 3, $243-247$. [CrossRef]

129. Okazaki, K.; Yanagawa, M.; Mitsuyama, T.; Uchida, K. Recent Advances in the Concept and Pathogenesis of IgG4-Related Disease in the Hepato-Bilio-Pancreatic System. Gut Liver 2014, 8, 462-470. [CrossRef]

130. Nayar, M.; Charnley, R.; Scott, J.; Haugk, B.; Oppong, K. Autoimmune pancreatitis with multiorgan involvement. A case of pericardial involvement. JOP 2009, 10, 539-542.

131. Horie, K.; Tada, N.; Yamaguchi, K.; Inazawa, K.; Endo, M.; Inoue, N. Immunoglobulin G4-related constrictive pericarditis identified by cytological examination of pericardial effusion: A case report. J. Med Case Rep. 2016, 10, 359. [CrossRef] [PubMed]

132. Tajima, M.; Nagai, R.; Hiroi, Y. IgG4-Related Cardiovascular Disorders. Int. Hear. J. 2014, 55, $287-295$. 
133. Alharbi, A.; Almadi, M.; Szilagyi, A. An Unusual Cause of Upper Gastrointestinal Bleeding. Gastroenterology 2012, 142, 211-413. [CrossRef] [PubMed]

134. Hoes, J.N.; Jacobs, J.W.; Verstappen, S.M.; Bijlsma, J.W.; Van der Heijden, G.J. Adverse events of low- to medium-dose oral glucocorticoids in inflammatory diseases: A meta-analysis. Ann. Rheum. Dis. 2009, 68, 1833-1838. [CrossRef] [PubMed]

135. Ito, T.; Nakamura, T.; Fujimori, N.; Niina, Y.; Igarashi, H.; Oono, T.; Uchida, M.; Kawabe, K.; Takayanagi, R.; Nishimori, I.; et al. Characteristics of pancreatic diabetes in patients with autoimmune pancreatitis. J. Dig. Dis. 2011, 12, 210-216.

136. Lee, H.W.; Moon, S.-H.; Kim, M.-H.; Cho, D.H.; Jun, J.H.; Nam, K.; Song, T.J.; Park, D.H.; Lee, S.S.; Seo, D.-W.; et al. Relapse rate and predictors of relapse in a large single center cohort of type 1 autoimmune pancreatitis: Long-term follow-up results after steroid therapy with short-duration maintenance treatment. J. Gastroenterol. 2018, 53, 967-977.

137. Nakamura, A.; Ozawa, M.; Watanabe, T.; Ito, T.; Muraki, T.; Hamano, H.; Koinuma, M.; Kawa, S. Predictive Factors for Autoimmune Pancreatitis Relapse After 3 Years of Maintenance Therapy. Pancreas 2018, 47, 1337-1343. [CrossRef]

138. Xin, L.; Meng, Q.Q.; Hu, L.H.; Lin, H.; Pan, J.; Hao, L.; Liu, P.P.; Qian, W.; Wang, L.W.; Li, Z.S. Prediction and Management for Relapse of Type 1 Autoimmune Pancreatitis After Initial Steroid Treatment: A Long-Term Follow-up From China. Pancreas 2018, 47, 1110-1114.

139. Miki, M.; Fujimori, N.; Oono, T.; Kawabe, K.; Ohno, A.; Matsumoto, K.; Teramatsu, K.; Tachibana, Y.; Ogawa, Y. Relapse patterns and predictors of IgG4-related diseases involved with autoimmune pancreatitis: A single-center retrospective study of 115 patients. J. Dig. Dis. 2019, 20, 152-158.

140. Ishii, Y.; Serikawa, M.; Sasaki, T.; Fujimoto, Y.; Yamaguchi, A.; Ogawa, T.; Noma, B.; Okazaki, A.; Yukutake, M.; Ishigaki, T.; et al. Impact of sclerosing dacryoadenitis/sialadenitis on relapse during steroid therapy in patients with type 1 autoimmune pancreatitis. Scand. J. Gastroenterol. 2019, 54, 259-264.

141. Kubota, K.; Iida, H.; Fujisawa, T.; Yoneda, M.; Inamori, M.; Abe, Y.; Kirikoshi, H.; Saito, S.; Ohshiro, H.; Kakuta, Y.; et al. Clinical factors predictive of spontaneous remission or relapse in cases of autoimmune pancreatitis. Gastrointest. Endosc. 2007, 66, 1142-1151. [PubMed]

142. Miyazawa, M.; Takatori, H.; Shimakami, T.; Kawaguchi, K.; Kitamura, K.; Arai, K.; Matsuda, K.; Sanada, T.; Urabe, T.; Inamura, K.; et al. Prognosis of type 1 autoimmune pancreatitis after corticosteroid therapy-induced remission in terms of relapse and diabetes mellitus. PLoS ONE 2017, 12, e0188549. [CrossRef] [PubMed]

143. Tacelli, M.; Celsa, C.; Magro, B.; Barresi, L.; Guastella, S.; Capurso, G.; Frulloni, L.; Cabibbo, G.; Cammà, C. Risk Factors for Rate of Relapse and Effects of Steroid Maintenance Therapy in Patients With Autoimmune Pancreatitis: Systematic Review and Meta-analysis. Clin. Gastroenterol. Hepatol. 2019, 17, 1061-1072. [CrossRef] [PubMed]

144. Ohno, Y.; Kumagi, T.; Yokota, T.; Azemoto, N.; Tanaka, Y.; Tange, K.; Inada, N.; Miyata, H.; Imamura, Y.; Koizumi, M.; et al. Early pancreatic volume reduction on CT predicts relapse in patients with type 1 autoimmune pancreatitis treated with steroids. Orphanet J. Rare Dis. 2016, 11, 103. [CrossRef] [PubMed]

145. Hart, P.A.; Topazian, M.D.; Witzig, T.E.; Clain, J.E.; Gleeson, F.C.; Klebig, R.R.; Levy, M.J.; Pearson, R.K.; Petersen, B.T.; Smyrk, T.C.; et al. Treatment of relapsing autoimmune pancreatitis with immunomodulators and rituximab: The Mayo Clinic experience. Gut 2013, 62, 1607-1615. [PubMed]

146. Akiyama, M.; Takeuchi, T. IgG4-Related Disease: Beyond Glucocorticoids. Drugs Aging 2018, 35, $275-287$. [CrossRef] [PubMed]

147. Matsushita, M.; Ikeura, T.; Fukui, T.; Uchida, K.; Okazaki, K. Refractory autoimmune pancreatitis: Azathioprine or steroid pulse therapy? Am. J. Gastroenterol. 2008, 103, 1834-1835. [PubMed]

148. Rovati, L.; Lanzillotta, M.; Bozzolo, E.; Arcidiacono, P.G.; Falconi, M.; Dagna, L.; Della-Torre, E. Methotrexate as Induction of Remission Therapy for Type 1 Autoimmune Pancreatitis. Am. J. Gastroenterol. 2019, 114, 831-833. [CrossRef]

149. Buechter, M.; Klein, C.G.; Kloeters, C.; Schlaak, J.F.; Canbay, A.; Gerken, G.; Kahraman, A. Tacrolimus as a Reasonable Alternative in a Patient with Steroid-Dependent and Thiopurine-Refractory Autoimmune Pancreatitis with IgG4-Associated Cholangitis. Z. Gastroenterol. 2014, 52, 564-568. 
150. Lazarevic, I.; Banko, A.; Miljanovic, D.; Cupic, M. Immune-Escape Hepatitis B Virus Mutations Associated with Viral Reactivation upon Immunosuppression. Viruses 2019, 11, 778.

151. Matsushita, M.; Yamashina, M.; Ikeura, T.; Shimatani, M.; Uchida, K.; Takaoka, M.; Okazaki, K. Effective steroid pulse therapy for the biliary stenosis caused by autoimmune pancreatitis. Am. J. Gastroenterol. 2007, 102, 220-221. [PubMed]

152. Sugimoto, M.; Takagi, T.; Suzuki, R.; Konno, N.; Watanabe, K.; Nakamura, J.; Kikuchi, H.; Waragai, Y.; Asama, H.; Takasumi, M.; et al. Efficacy of Steroid Pulse Therapy for Autoimmune Pancreatitis Type 1: A Retrospective Study. PLoS ONE 2015, 10, e0138604.

(C) 2019 by the authors. Licensee MDPI, Basel, Switzerland. This article is an open access article distributed under the terms and conditions of the Creative Commons Attribution (CC BY) license (http://creativecommons.org/licenses/by/4.0/). 